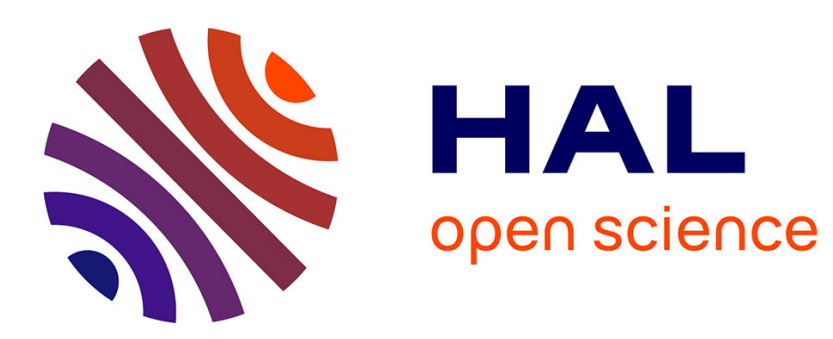

\title{
Adjusting content to individual student needs: Further evidence from an in-service teacher training program
}

Adrien Bouguen

\section{To cite this version:}

Adrien Bouguen. Adjusting content to individual student needs: Further evidence from an in-service teacher training program. 2015. halshs-01128184v2

\section{HAL Id: halshs-01128184 \\ https://shs.hal.science/halshs-01128184v2}

Preprint submitted on 10 Dec 2015

HAL is a multi-disciplinary open access archive for the deposit and dissemination of scientific research documents, whether they are published or not. The documents may come from teaching and research institutions in France or abroad, or from public or private research centers.
L'archive ouverte pluridisciplinaire HAL, est destinée au dépôt et à la diffusion de documents scientifiques de niveau recherche, publiés ou non, émanant des établissements d'enseignement et de recherche français ou étrangers, des laboratoires publics ou privés. 


\title{
ADJUSTING CONTENT TO INDIVIDUAL STUDENT NEEDS: FURTHER EVIDENCE FROM AN IN-SERVICE TEACHER TRAINING PROGRAM]*
}

\author{
Adrien Bouguen $\|^{\dagger}$
}

November 8, 2015

\begin{abstract}
Adapting instruction to the specific needs of each student is a promising strategy to improve overall academic achievement. In this article, I study the impact of an intensive in-service teacher training program on reading skills offered to kindergarten teachers in France. The program modifies the lesson content and encourages teachers to adapt instruction to student needs by dividing the class according to initial achievement. While assessing impact is usually difficult due to the presence of ability bias and teacher selection, I show that in this context, a value-added model that controls for school and teacher characteristics constitutes a legitimate strategy to estimate the treatment effect. Results show that all students benefiting from the program progressed in reading skills at the end of the year. Besides, weaker students progressed faster on less-advanced competences (such as letter recognition), while stronger students improved their reading skills. This suggests that teachers adjusted content to students' needs. Finally, a cost-effectiveness analysis reveals that the program is approximately three times more cost-effective than reducing class size in France.
\end{abstract}

JEL classification: I21, I24

Keywords: Early childcare program, teacher training, teaching practices and content, inequality

*This research was funded by a grant from the "Fond d'Expérimentation de la Jeunesse" and by "Agir pour l'Ecole". This work has been realized with the support of the Statistical department of the National Education in France (DEPP) and of NGO "Agir pour l'Ecole" (APE). Special thanks to Laurent Cros (APE) and Alice Bougnères (APE) for their constant support and to Thierry Rocher, Sandra Andreu and Marion Le Cam (DEPP) without whom this work would not have been possible. I wish to express my gratitude to the 118 schools and their teachers who have participated as beneficiary or not to the data collection. I also thank Marc Gurgand, Eric Maurin, Camille Terrier, Julien Grenet for their useful comments during the seminar in Paris. Likewise, comments from Sandra Mc Nally, Clément Malgouyres, Maxime To after the Institute of Education (UCL) seminar in London were all very useful.

${ }^{\dagger}$ Paris School of Economics, 48 boulevard Jourdan Paris, adrien.bouguen@ipp.org 
The existence of large variation in teacher quality is indicative of the central role that teacher plays in the overall performance of an education system. The most reliable studies suggest that a one standard deviation increase in teacher quality raises student performance by at least $9.5 \%$ of a standard deviation 1 a magnitude that is equivalent to a 5 - to 10 year increase in teaching experienc $\mathrm{L}^{2}$ or to a class size reduction of $4-5$ children $\bigsqcup^{3}$ Giving the right incentives, selecting the right teachers, and providing them with the right skills are all being investigated as potential ways to improve teaching in both developed and developing settings. The latter solution - pre-service and in-service teacher training has been widely studied in developed countries. Teacher-training programs are appealing because, when effective, they are potentially a cost-efficient and lasting strategy to enhance student achievement $4^{4}$ Available empirical results are not always consistent, however, and the literature is still unable to reach consensus on the effectiveness of teacher training.

Four main challenges plague the literature on teacher training. First, it has proven difficult to isolate the causal effect of training from the effect of selection into training ("teacher selection") and the effect of assignment of trained teachers to students ("student selection"). Second, isolating the effect of training from other policies implemented at the same time is sometimes challenging. Third, the vast diversity of teacher training programs - in term of content, nature, level, intensity, or even quality - renders difficult any sort of general statement on the effectiveness of such policy; a more refined approach is needed to parse what may be effective from what is not. Fourth, as mentioned, while teacher training programs are cheap when compared to programs that directly target students, they have only little effect on them (typically around $10 \%$ of a standard deviation). Lack of detection

\footnotetext{
${ }^{1} 9.5 \%$ is the effect found by Rivkin et al. 2005), and $10 \%$ by Rockoff (2004), using a different strategy, correcting for overestimation due to measurement error. Using simple teacher fixed effect, the literature review provided by Nye et al. (2004) gives effects from .26 to .46. Applying the same naive strategy on my data, I find consistent effects from .19 to .39, depending on the cognitive measure used.

${ }^{2}$ Hanushek (1971), Rockoff (2004), or more recently Harris and Sass (2011) all provide estimations varying from $1 \%$ to $2 \%$ of a standard deviation per year of experience. As we will see, I provide a slightly smaller estimation of the teacher experience effect (around $0.9 \%$ ), maybe because experience is less meaningful in preschool than in primary school. Note that, for comparison matter, I report the experience effects per year, although this is probably not the most meaningful way. Most authors are able to identify a nonlinear relationship in which the experience effect is strongest during the first years and reaches a cutoff year above which experience is not predictive anymore. Due to lack of power, I am not able to implement such a model.

${ }^{3}$ This is based on a class size effect estimated between $2.2 \%$ and $3 \%$ per additional pupil in class (Bressoux et al. 2009, Bressoux and Lima, 2011, Piketty and Valdenaire, 2006). Note, however, that this estimate is clearly larger than the one found with STAR data (1.7).

${ }^{4}$ Training one teacher "treats" many students at once, and if "good" teaching practices are employed throughout the teacher's career, these practices may have an effect on several generations of students.
} 
power has affected the quality of some studies.

This article alleviates some of these concerns. Results are based on a non-randomized empirical settings whereby treatment schools benefiting from the program are designated by the school district managers and the control schools are selected by the research team based on some school level characteristics. With precise data at the student level collected at baseline and endline, it is possible to use value added models to contrast the progress observed in treatment schools with the ones observed in similar control schools. Such design is potentially undermined by (1) selection bias (from teacher, school or even parents) and (2) by students naturally $5^{5}$ progressing at different pace. While data at the teacher and school level are used to address the first difficult, I show that in this context - hereby when the treatment group is originally weaker than the control group - and under some (restrictive) assumptions, a value added model simply controlling for baseline test scores (VAM 1) give a low bound of the true treatment effect and should be preferred to a difference in differences model (VAM 2).

The results indicate that well-defined and intensive pedagogical training (based on explicit teaching, phonological awareness $\sqrt{6}^{6}$ and small group tracking), well-monitored, when applied to one specific subject (reading) during one specific period of teaching time (when pupils start reading lessons, around 5 years old) is instrumental in improving kindergarten children's short-term reading achievement. I find an overall treatment effect of $15.3 \%$ of a standard deviation with results varying from no effect on the dimensions not stimulated by the program (vocabulary, comprehension) up to $44 \%$ of a standard deviation in decoding (non-lexical reading). A back-of-the-envelope cost-benefit calculation gives $12.5 €$ per percentage point of standard deviation gain: less cost-effective than a similar experiment run in England (see Section 2), but still much less expensive than my assessment of a class size reduction policy implemented in France (between $36-48 €$ per s.d.).

While small in magnitude, $8.3 \%$ of a standard deviation is arguably a very cost-effective strategy. In England, the cost was as low as $38 €$ per child, or $5 €$ per percentage point of a

\footnotetext{
${ }^{5}$ Naturally in the sense that their progresses are not triggered by different schools or students but may be influenced by other unobserved factors such as nature (weak students naturally progress faster for instance) or parents.

${ }^{6}$ To simplify, I will use phonology and phonological awareness interchangeably and define the concept as the ability to hear, repeat, mix, and decompose sounds, and to link them to graphemes. I will also regroup under the term "phonological awareness" concepts such as phonics (the ability to link sounds to graphems) or phonemic awareness (the ability to mix sounds), which are not necessarily equivalent but closely related. To match the wording of some other authors, I will sometimes use the term "code-related skills," which regroup both phonological awareness and letter recognition.
} 
standard deviation gain. In comparison, class size reduction programs have been reported to increase student performance from $+2.2 \%$ to $+3 \%$ of a standard deviation per child in French primary schools (Bressoux et al., 2009, Bressoux and Lima, 2011, Piketty and Valdenaire, 2006), for a cost of about $107 €$ per child, or 36 -48 $€$ per percentage point of standard deviation gain?7; all being equal, a "Literacy Hour" training program implemented in France would then be at least eight times more cost-effective then a class-size reduction. As said, the program evaluated here is more effective, more costly, but less cost-effective than the English experiment, but is at least three time more cost effective expensive than a class-size reduction program.

Equally important are the heterogeneous effects found by initial achievement. Since the training program was based on an explicit teaching pedagogy implemented on four groups of initial achievement (tracked group), one of the expectations was that the program would help teachers instruct at the right level. Heteregeneous effect by initial achievement shows that initially weaker-performing students progressed faster on less-advanced competences (letter recognition, phonological awareness), while initially stronger-performing students progressed faster on more-advanced competences (reading and-non reading skills). These results suggest that the training programs have indeed helped teachers adjust content to all students' needs. Such results echo those found in a very different context by Banerjee et al. (2010, 2007), Duflo et al. (2011), where teaching to the right level was particularly effective in improving all students' achievements. The results presented in the following, therefore, provide further evidence that adjusting content to every student's needs - whether via tracking, within-class tracked groups, or via a new pedagogy - is instrumental in improving student achievement. I believe that this is the first time such result is presented in a developed country and in an experimental environment that is arguably very close to the existing institutional context.

The conceptual framework developed in Section 2 suggests that, under some restrictive assumptions, simple regression results, controlling for baseline test scores provide a low bound of the true treatment effects. The empirical part, Section 3, shows that results are robust to inclusion of both school and teacher characteristics and that attrition seems not

\footnotetext{
${ }^{7}$ This is an approximate assessment of the overall cost of the reduction of one pupil per class in primary school. It is based on an average net monthly teacher salary of 2323 €in France, multiplied by two to account for social contributions, and then multiplied by 12 months, to which I add an administrative cost of $15 \%$. Since in my data set, class size is in average composed of 25 students, a reduction by 1 student is equal to $(2323 * 2 * 1.15 * 12) / 24-(2323 * 2 * 1.15 * 12) / 25 \approx 107 €$.
} 
to have affected results in any particular direction. Finally, the program trains teachers to a pedagogy that is sufficiently standard to be compared to the one used in at least three other contexts (France, the United States and England). Contrasting the results from these three contexts to the ones found here allows for more specific conclusions.

In the rest of the article, I will describe and expand upon the available literature. I will then develop a simple empirical model that clarifies the conditions in which the valueadded models used in this article properly identify the teacher program effect. I will also present how pre-schooling is organized in the French education system and give details on the training program. Finally, I will describe the school, teacher, and student-level data on which my analysis relies, and I will present my results. I conclude by contrasting my results with three other comparable studies.

\section{Literature Review}

The literature on teacher training is indirectly related to studies about the pre-service teacher qualification and teacher certification. This litterature shows only weak relations between the initial training received by teacher and their performance at school. Most authors - Kane et al. (2008) in New York City, Goldhaber et al. (2013) in Washington, Koedel et al. (2012) in Missouri, and Harris and Sass (2011) in Florida - concludes that the large teacher variation in performances are only weakly explained by the training received during certification or by the teacher education. As argued by Eric Hanushek (Hanushek, 1971, Rivkin et al., 2005), selecting the right teachers seems to be a much more cost-effective strategy than training the wrong ones.

Yet, as mentioned by Goldhaber et al. (2013), this literature is not directly interested in the effect of training as it compares different sorts of training programs and looks at the heterogeneous offer of teacher preparation available in some regions in the United States. It does not say much about the kind of training that a teacher should receive, or whether investment in teacher training should be preferred to extensive education policies such as class size reduction. Relating more to my purpose, Boyd et al. (2009), using the same New York City panel data used by Kane and Staiger (2008), found that teachers who received more practical preparation - those who are more prepared for the curriculum and have more classroom experience - are more likely to perform slightly better in their first teaching years. Although small in magnitude, such effects suggest that teacher training content matters, 
and more specific and intensive training might be instrumental in improving teacher quality.

This claim is supported by other articles that look at the net effect of intensive teacher training programs. In France, for instance, Bressoux et al. (2009) have compared the student performances of two cohorts of newly recruited primary school teachers, one which has benefited from two years of primary school preparation, and the other which has received no training at all. The authors find a strong and significant impact in mathematics (+.25 standard deviation), but not in reading. Likewise, in Israel, Angrist and Lavy (2001) investigated the effect of an intensive in-service training (five hours per week) and showed very strong results (+.3 s.d.). When comparing these with the aforementioned results from the US, it is worth noting that in both cases, the authors contrast very intensive training programs (a two-year pre-service training in France and a five-hour-per-week training in Israel) to a counterfactual which receives no training at all. Yet, as very little is known about the content of each training, these two local examples are difficult to compare, and results may be context-specific. As mentioned before, the diversity of contexts (developed and less developed), of training content and intensity, of the multitude of dimensions that can be stimulated, of the multitude of subjects (mathematics, literacy, science, and so on) and of grades make any general statement about teacher training per se not fully meaningful.

To avoid such general statements, this article analyzes the effects of well-defined pedagogical training, based on explicit teaching 8 and aiming at strengthening code-related early skills (with a strong emphasis on the recognition of letters and sounds, as well as phonological awareness), and applied to one specific subject (reading) at one specific period of teaching time (when pupils learn how to read between the ages of 5 and 7 years). The focus on phonological awareness at an early stage (before the official beginning of reading classes) is justified by a vivid psychological literature that explores the foundation of reading success and links code-related early skills to grade 1/grade 2 reading skills. Using a longitudinal three-year panel data of children aged 5 to 8, Schatschneider et al. (2004) confirm the interest of focusing on phonological awareness at early stages by showing the strong predictive power of code-related skills (letter recognition, sound recognition, and

\footnotetext{
${ }^{8}$ There is no clear definition of "explicit teaching," but the general idea is that the method promotes a very structured pedagogy where teaching content is adjusted as much as possible to student progress, clear objectives are set, and specific tasks are completed before accessing new tasks. Such an approach is defended by Success For All, an influential NGO in the US and UK. It is often opposed to exploratory teaching such as the inquiry-based learning defended by alternative education models such as Montessori.
} 
phonological awareness). While still debated $!^{9}$ this view is in line with the conclusions of the National Reading Panel (1999), which canvassed a large body of evidence on literacy in the 90 s in the US.

To my knowledge, only two reports from the Institute of Education Studies, as well as two scientific articles, can be directly compared with the results of this article. Both IES reports, which rely on randomized experiments, find no effect of the teacher training programs Garet et al., 2008, 2011). The older report is particularly meaningful for my purpose, as it evaluates the effect of a training program aimed at improving first graders' reading skills. This training program, as is the case here, is based on the findings of the National Reading Panel (see Section 4.3 below, where the training program is described). Also similar to the program studied here is the one implemented recently in France where researchers analyzed the impact of a similar teaching pedagogy in first grade, again with no results on student achievement (Gentaz et al., 2013). Finally, using a cross section difference-in-differences strategy on a large dataset, Machin and McNally (2008) were able to convincingly identify an overall effect of $8.3 \%$ of a standard deviation in England from a training program called the "Literacy Hour," which resembles those evaluated both in France and in the US. It could be argued that these three results are not necessarily inconsistent, as both randomized experiments could only satisfactory identify effects above .22 s.d. (Garet et al., 2008) and .25 s.d. (Gentaz et al. 2013) ${ }^{10}$ far from the $8.3 \%$ found in England 11

\footnotetext{
${ }^{9}$ As summarized by NICHD $(2005)$, there is a fierce debate in the psychological research on the respective predictive power of code-related skills versus oral language skills (early vocabulary or comprehension). Earlier work from Storch and Whitehurst (2002) suggests that while code-related skills predict early and mid-early skills (end of grade 1), later reading skills (grade 4) are best predicted by oral language skills. Yet several other articles conclude in radically different ways Schatschneider et al. (2004). To my understanding of the literature, much of the results hinge on (1) the quality of the data and (2) the test scores used to assess endline reading skills. A middle-ground position might be to consider code-related skills as necessary, but not sufficient, steps in the road to reading, justifying the focus on phonological awareness at early stages.

${ }^{10}$ I recalculate the Minimum Detectable Effect (MDE) using data provided by the authors (see Gentaz et al. (2013), 48 classes, composed of 23 students, 21 classes in treatment 27 in control with an intercluster correlation and a baseline-endline correlation assumed respectively at $10 \%$ and $30 \%$. This gives $\mathrm{MDE}=\frac{2.8}{\sqrt{\left.\left(\frac{21}{48}\right) *\left(\frac{27}{48}\right) * 48\right)}} * \sqrt{0.1+\frac{0.9}{23}} * \sqrt{1-0.3}=.25$

${ }^{11}$ It seems that the researchers in France and in the US were misguided by the very optimistic effect sizes reported in the National Reading Panel. According to the National Reading Panel (1999), a phonological awareness pedagogical approach should increase student achievement by at least $60 \%$ of a standard deviation. Such optimistic results were in fact obtained in very controlled environments, on small samples and with supposedly motivated teachers. When implemented in "real life," such programs seem to yield a much more moderate impact.
} 


\section{2 conceptual framework}

\section{$2.1 \quad$ Model}

Achievement in period 1 (after the training program) can be modeled by four additive effects:

$$
A_{i 1}=\beta T_{s}+\mu_{i}+\iota_{i 1}+\epsilon_{i 1}
$$

$\mathrm{T}$ is the teacher training provided to all teachers in school $\mathrm{s}, \mu_{i}$ is the fixed capacity of student $i, \mathfrak{l}_{i 1}$ is the non-fixed capacity effect (later called "ability to progress"), and $\epsilon_{i 1}$ is the measurement error, unrelated to any observed and unobserved characteristics. In this model, $\beta$ measures the effect of the teacher training on the pupil $i$.

In a non-randomized setting, a main source of worry is $\iota_{i 1}$ ("ability to progress") that can be correlated with both $\mathrm{T}$ and $\mu . \iota_{i 1}$ can hence be decomposed as follows:

$$
\iota_{i 1}=\rho \mu_{i}+v_{i 1}
$$

where $\rho$ is a measure of the correlation between $\mu$ and $\mathbf{l}$, and $v$ is the part of the progression that is unrelated to the initial endowment. To rephrase, $\rho \mu_{i}$ is a part of the progression due to the child, and $v_{i}$ is the external shock: typically teacher, school, or parental involvement effect. Besides, the sign of $\rho$ indicates the underlying students' progression model. $\rho>0$ indicates a model where students' achievement tends to diverge naturally over the year: weaker students progress at a slower pace than advanced ones. Inversely, $\rho<0$ indicates that weaker students tend to catch up with the rest of the class, while $\rho=0$ indicates that progress is unrelated to students' initial level, and hence all children have a common progression trend.

Inserting (2) in (1) gives:

$$
A_{i 1}=\beta T_{i 1}+(1+\rho) \mu_{i}+v_{i 1}+\epsilon_{i 1}
$$

Similarly, achievement at time 0 can be defined as:

$$
A_{i 0}=\mu_{i}+\epsilon_{i 0}
$$


Note $\mathfrak{l}_{\mathfrak{i} 0}$ is here normalized in $\mu_{i}$. It follows that achievement at time 1 can be written:

$$
\begin{aligned}
A_{i 1} & =\beta T_{i 1}+\mu_{i}+\iota_{i 1}+\epsilon_{i 1} \\
& =\beta T+(1+\rho) \mu_{i}+v_{i 1}+\epsilon_{i 1} \\
& =\beta T+(1+\rho) A_{i 0}+v_{i 1}+\epsilon_{i 1}-(1+\rho) \epsilon_{i 0}
\end{aligned}
$$

Note that neither $v$ and $\iota$ appears in 5 indicating that both initial level and progressing which is related to achievement is accounted for in any value added model. Yet, estimating

5 still faces two remaining issues. A measurement issue: as $A_{i 0}$ is correlated to $\epsilon_{\mathfrak{i} 0}$, estimating $(1+\rho)$ will suffer from an attenuation bias due to measurement error which would in turn bias $\beta$. Second, a selection issue, because $v_{1 i}$ is uncontrolled for shocks unrelated to achievement (such as being enrolled in a better functioning schools, benefiting from a good teacher, or from good parents) that will bias the estimation if they are related to $\mathrm{T}$.

\subsection{Value-Added Models and Lower Bound Estimates}

Putting aside the second concern and hence assuming:

$$
E\left(v_{i 1} \mid T\right)=0
$$

two strategies are traditionally used to cope with the measurement issue(i.e. estimating $1+\rho)$. In the first model, later called value added Model 2 (VAM2), $\rho$ is constrained to zero, and then each student progression is regressed against treatment variable. Hence, from (5), VAM2 strategy gives:

$$
\begin{aligned}
A_{i 1} & =\beta T+A_{i 0}+v_{i 1}+\epsilon_{i 1}-\epsilon_{i 0} \\
A_{i 1}-A_{i 0} & =\beta T+v_{i 1}+\epsilon_{i 1}-\epsilon_{i 0}
\end{aligned}
$$

Under 6, $\beta$ is consistently estimated using a simple OLS regression model. Besides, according to 2, $\rho=0$ means that the initial endowed capacities will not influence students' progression; e.g., weaker students will not spontaneously catch up with the rest of the class 
(or inversely). This is another way to express the common trend assumption, and (6) is commonly called a difference in differences estimation.

Since imposing a constant progression among young children may not be an acceptable assumption, especially in an education setting, ${ }^{12}$ one may want to relax this constraint. Relaxing the constraint on $\rho$ supposes to estimate $1+\rho$ in the following model:

$$
A_{i 1}=\beta T+\gamma A_{i 0}+v_{i 1}+\epsilon_{i 1}-\gamma \epsilon_{i 0}
$$

with $\gamma=1+\rho$. As in 5 , because $\mathrm{E}\left(\epsilon_{i 0} \mid A_{i 0}\right) \neq 0, \hat{\gamma}$ will be downward biased. What consequence would such bias have on $\hat{\beta}$ ? We know that it is likely to be biased, as $\mathrm{T}$ and $A_{i 0}$ are likely to be correlated. But can the direction of the bias be derived?

Using a well-known result from the omitted variable biased model, considering $\epsilon_{0}$ as the omitted variable, it can be shown (see appendix A) that:

$$
E\left(\hat{\beta}_{v \mathrm{am} 1}\right)=\beta+\gamma \frac{r\left(A_{0}, T\right) * V_{\epsilon_{0}}}{1-r\left(A_{0}, T\right)^{2}} \frac{S_{\epsilon_{0}}}{S_{T}}
$$

With $r\left(A_{0}, T\right)$, the correlation between baseline test score $A_{0}$ and $T, V_{\epsilon_{0}}$ the variance of the baseline measurement error, $S_{\epsilon_{0}}$ its standard deviation, and $S_{\mathrm{T}}$ the standard deviation of the treatment group. With $\gamma=1+\rho>0$, the sign of the bias is fully determined by $r\left(A_{0}, T\right)$. Since, in this study, the treatment group's students were initially weaker than the ones enrolled in control group schools, $r\left(A_{0}, T\right)<0$ and $\hat{\beta}_{v a m 1}$ is the value added model 1 gives a low bound of the true treatment effect (still under assumption 6). I will hence rely on VAM1, keeping VAM2 only as a benchmark.

\subsection{Coping with the Selection Issue}

This is, of course, leaving the second issue aside, i.e. assuming $E\left(v_{i 1} \mid T\right)=0$. Different $v_{i 1}$ may be due to children themselves (children in the treatment school happened to have a different ability to progress, even conditional on their endowed capacities), to their parents (parents may be more involved in one of the two groups or may compensate low school

\footnotetext{
${ }^{12}$ In this context, with the outcomes being early reading skills (decoding, phonology, and so on), one may expect that initial differences may be reduced when the first classes are given. A convergent model where $\rho<0$ is hence more likely, although there is no tangible evidence of such a pattern.
} 
or teacher performance), to the school (school administration may be different), or to the teacher (some teachers may simply be better in treatment than in control). Obviously, one major concern is the selection at the teacher level, as the training program is directed to them. If only volunteer teachers (or schools) participated in the teacher training, we may expect $v_{i 1}>0$ and the estimation to be biased upward. Alternatively, if school district administrators have chosen the schools that were the most in need of training, bias might be reversed.

As we will see, in that case, the school district managers were asked to select the schools in which the program was the most needed. Although they were in a position to impose the training program in any specific school, they have most likely asked the opinion of the school directors and maybe of teachers. Participation was hence decided between the teachers, the school director, and the school district manager. In any case, I do not believe that other sources of bias (either parents or children) have ruled over this decision.

To investigate whether a selection at school or teacher level has occurred, I will rely on additional data from the school and the teacher, and estimate modified version of value added model 1 accordingly:

$$
A_{i 1}=\beta T+(1+\rho) A_{i 0}+\kappa_{i 1}+P_{c 1} \alpha+S_{s 0} \alpha_{2}+\epsilon_{i 1}-(1+\rho) \epsilon_{i 0}
$$

where $\mathbf{P}_{\mathrm{c} 1}$ is a matrix of teacher level characteristics collected at follow-up ${ }^{13}$ and $\mathbf{S}_{\boldsymbol{0}}$ a set of school level characteristics collected at baseline. Both sets of control variables are supposed to remove any correlation between $\kappa_{i 1}$ and $\mathrm{T}$ and make :

$$
E\left(\kappa_{i 1} \mid T, A_{i} 0, P_{c 1}, S_{s 0}\right)=0
$$

a valid assumption. As shown in the appendix, under assumption (12), (11) estimated with a VAM1 still provides a low bound of the true treatment effect.

There are yet at least two reasons we might not be fully satisfied by this strategy. First, teacher characteristics were collected from teachers themselves after the training

\footnotetext{
${ }^{13}$ Although we would ideally want to control for information collected before the inception of the training program, this was not possible. The teacher characteristics were collected one year after the end of the program. Yet I rely essentially on constant information or information that is unlikely linked to the program.
} 
programs, and were thus potentially affected by the intervention. The intervention may have impacted the way teachers answer, their practices, and also their propensities in responding (attrition bias). Second, we may be worried that both teacher and school characteristics are imperfectly measured (Hanushek (1986), Hanushek et al. (2005)). In the forthcoming empirical part, however, I will show that among the few variables collected at teacher level, some are predictive of the teacher value added and are effectively removing teacher selection.

Taken together, the conclusions drawn from this model present rather favorable experimental settings. In the absence of school or teacher selection, and since treatment students were initially weaker, the treatment effect estimated with VAM1 can serve as a lower bound of the treatment effect. Using school and teacher data, I will show why selection at school or teacher level is probably not a major concern. After having quickly described the data and the context, I will analyze precisely both sources of bias and try to find an empirical solution for both.

\section{The Kindergarten Intervention within the French Educational System}

\subsection{The French Educational System}

In France, the educational system is organized in three tiers that mimic the political organization. The three tiers are under the central authority of the Ministry of National Education. The highest tier, the Regional School District (rectorat), is at the regional level ${ }^{14}$ The middle tier, the Departmental School District (Inspection d'Académie), is at the sub-regional level (d'épartement). The lowest tier, the School District (Inspection de l'Education Nationale), is the first authority above the school director and the teachers. School district managers have a direct authority over the school directors and the teachers of his or her ward (circonscription). Importantly, they are responsible for teachers' assessment (inspection), which partly determines teachers' wage increases and transfer possibilities (mutation).

As we will see in the following section, the training program's evaluation was imple-

\footnotetext{
${ }^{14}$ This is subject to some exceptions. Large regions such as Ile de France (suburban Paris) are, for instance, divided into three regional school district (Créteil, Versailles, and Paris).
} 
mented in three rectorats (Créteil, Versailles, and Lille), two rectorats situated in suburban Paris (Créteil and Versailles), and one in the region Nord (Lille's region). The three rectorats authorized the experiment in four department school districts: two in Lille (numbers 59 and 62), and two in suburban Paris (numbers 92 and 93). In each department school district, the program was implemented in two school districts, hence eight in total. The original sample was composed of 59 beneficiary schools and 59 control schools.

\subsection{Kindergarten in France}

In France, a three-year-old child (or a child who will turn three before the end of the calendar year) is allowed to be enrolled in the first year of kindergarten. Kindergarten is free of charge, and the education provision is organized at the national level by the Ministry of Education (teachers are paid by the central state, with the curriculum designed nationally). While enrollment at three is not compulsory, enrollment rate at that age is near 100\% (DEPP, 2013). Kindergarten is composed of three school years: Petite Section $(P S)$, Moyenne Section (MS) and Grande Section (GS). Kindergarten teachers must follow a national curriculum specific to each year. This curriculum is agreed upon at the national level and is published in the Bulletin Officiel de l'Education Nationale (official ministry register) whenever it is modified 15 So far, the kindergarten curriculum has been relatively nonrestrictive, leaving much freedom to teachers; the curriculum does not impose any specific teaching methods, nor does it provide guidance on how school days should be broken up or how progress should be organized over the school year. It only gives general objectives to be met at the end of kindergarten. In that sense, the last 2008 curriculum respects the general principle of liberté pédagogique(teaching freedom), a principle that is recognized by law ${ }^{16}$ This principle is probably more manifest in kindergarten than in primary school, when curricula start to be more precisely specified.

Nonetheless, in the "GS's national curriculum, teachers are asked to start developing phonological awareness ${ }^{17}$ i.e. (1) connecting sounds and letters (phonemics) and decomposingwords into syllables (phonological awareness). According to the report of the

\footnotetext{
${ }^{15}$ The last version of the kindergarten curriculum was published in the Bulletin Officiel in June 2008. See Bulletin Officiel hors-série $n^{\circ} 3$ du 19 juin 2008.

${ }^{16} \mathrm{See}$, for instance, article 48 from Loi d'orientation et de programme pour l'avenir de l'école L. ${ }^{\circ}$ 2005-380 du 23-4-2005. JO du 24-4-2005.

${ }^{17}$ distinguer les sons de la parole and aborder le principe alphabétique, BO hors série n ${ }^{\circ} 3$ du 19 Juin 2008.
} 
National Reading Panel (NRP), both skills are supposed to constitute the first phase of reading, and failure to master them is strongly predictive of reading difficulties in first grade (National Reading Panel, 1999).

\subsection{Training Intervention: Changing the Teaching Practices}

In the wake of the conclusions of the National Reading Panel, an NGO called Agir pour l'école, in collaboration with researchers from Cogniscience at University Pierre Mendès France, designed a new reading pedagogy composed of teacher training sessions, books, and specific guidelines that promote an intensification of the amount of phonology in GS teaching. Although phonological awareness is recognized in the curriculum as one of the main skills to be developed in GS, there are reasons to believe that the level provided in French classes is not sufficient to prevent reading difficulties among the weakest pupils (Bougnères et al., 2014). The pedagogy defended by the NGO explicitly runs counter to the principle of pedagogical freedom, which prevails in the French educational system by giving explicit instructions for teachers to follow every week ("explicit teaching"). Teachers are asked to give two sessions of 30 minutes of phonological awareness per day, starting in January until the end of the school year. The trained teachers are expected to provide a total of 20 hours maximum phonological awareness, which is supposedly much higher than the amount received by a GS student in a standard school.

In addition, the methodology is designed to be implemented in small groups of 5-6 children with similar achievement levels ("tracked achievement groups"). Again, the idea is to counteract another potentially detrimental practice that provides the same content to the whole class, regardless of individual pupil's development stage. At the beginning of the year, all GS pupils' early phonological awareness is assessed, and four achievement groups are created ${ }^{18}$ Each small group has a certain number of exercises that must be completed before moving to the next stage. The idea is to insure that the teaching content would stick to the progress of each child. Once again, this is supposedly different from the general practices in a standard French school.

To insure that the program is properly implemented, the NGO, in addition to training teachers, trains one pedagogical adviser $[9$ to the new methodology in each school district.

\footnotetext{
${ }^{18}$ Teachers were also allowed to modify the groups composition as they wished, but rarely did so in practice.

${ }^{19}$ conseiller pédagogique
} 
pedagogical adviser are responsible for monitoring the way the methodology was implemented on the field and could offer additional training hours (up to 18 hours). The NGO also directly monitored the implementation of the program by visiting numerous schools during the year. Although the original objective was to create a methodology that could be easily implementable in any context (through precise learning instructions), it seems relatively clear that the implication of the local education administration partly determines the effectiveness of the policy. Although I do not have extensive information on teacher practices, I will show in Table 3 that the program seems to have significantly modified the teacher practices.

\section{Data and Sample}

\subsection{Sample Creation}

The empirical analysis of the training program essentially relies on a sample created by the Bureau for Evaluation and Statistics of the Ministry of Education in France (DEPP). Fifty-nine treated schools were selected in three "rectorats" (Regional School Districts), four "IAs" (Departmental School Districts) and eight IENs (School Districts).It is not clear how schools within each treatment school district were recruited in the program; the school district managers possibly selected some schools eligible to participate (schools with a GS class and which had no other ongoing program), and these schools were then contacted by the NGO. As schools are under the direct authority of their managers, they cannot refuse to participate in a program supported by their manager. However, selection probably depended on the commitment of the manager into the program. All in all, if selection has happened at that stage, it would probably come more from the manager than from the schools themselves.

To create a credible control group, the DEPP selected schools situated in the same Departmental School District (but not in same School District), from the same priority education level ${ }^{20}$ and from schools composed of the same number of children. Based on

\footnotetext{
${ }^{20}$ At the time, schools could benefit from two levels of priority education RRS ("Réseau de Réussite Educative") or RAR ("Réseau Ambition Réussite"). RAR schools are composed of the most underprivileged children and are the primary target of the priority education policy. They notably receive additional financial support from the Ministry (teachers and teaching assistants). Children enrolled in RRS schools are less deprived and benefit from special policies from their regional school district ("Rectorat").
} 
these three criteria, 24 strata were created, and among the 1807 schools included in the sampling frame, the DEPP randomly selected 59 control schools (one for each treatment school).

If we believe that the few stratification variables used to select the 59 control schools are at least partially correlated with the outcome as well as school and teacher quality, the original sample should somehow be balanced in terms of school, teacher, and children characteristics. Of course, since treatment schools were selected by the School District manager (or were able to self-select into the treatment), one may worry that schools and teachers in the treatment and control branches would be initially different. In addition, as we will see in the coming subsections, attrition was relatively high.

\subsection{School-Level Data}

As shown in Table 1, not all schools complied with the initial evaluation design. Twentyone control schools did not administer the baseline test score, while only four did so in the treatment group. As shown in the first row of the table, the attrition rate before baseline is high and is significantly different between treatment and control schools (-28.8\%). It seems relatively clear that some control schools refused to administer the baseline test because they were not getting the benefit of the training program.

In Table 1, I also look at the more traditional attrition between baseline and followup. Although some additional schools did drop from the sample (15\%) between baseline and follow-up, this has not aggravated the differential attrition. As shown in row 3, final attrition is large $(32 \%)$ and differential (-27\%). Also, selection has occurred differently in the four Departmental School Districts (IAs) in which the program was implemented. In Lille's district, for instance (IA 59 and IA 62), the average attrition remains relatively low (around 20\%), and attrition is exactly similar in treatment and control group in IA 59 , where the implementation conditions were certainly the most favorable. The situation looks less favorable in the two IAs in the Parisian regions (IA 92 and IA 93): both display large average attrition rates, and attrition is significantly different in treatment and control. The reasons for these differences in compliance and implementation are down to the local context. While the program was well accepted by the teachers and pedagogical advisers in Lille, it was less positively received in IA 92 and 93. 
Table 1: School attrition

\begin{tabular}{|c|c|c|c|c|}
\hline & $\mathrm{N}$ & Average & $\mathrm{C}$ & $\mathrm{T}-\mathrm{C}$ \\
\hline Before baseline & 118 & 0.212 & 0.356 & $\begin{array}{c}-0.288^{* * *} \\
(0.071)\end{array}$ \\
\hline Between base- and end-line & 94 & 0.149 & 0.158 & $\begin{array}{c}-0.015 \\
(0.076)\end{array}$ \\
\hline Overall attrition & 118 & 0.322 & 0.458 & $\begin{array}{l}-0.271^{* * *} \\
(0.083)\end{array}$ \\
\hline ... from IA 59 & 18 & 0.222 & 0.222 & $\begin{array}{l}0 \\
(0.208)\end{array}$ \\
\hline$\ldots$ from IA 62 & 12 & 0.167 & 0.333 & $\begin{array}{c}-0.333 \\
(0.211)\end{array}$ \\
\hline$\ldots$ from IA 92 & 32 & 0.313 & 0.5 & $\begin{array}{c}-0.375^{* *} \\
(0.155)\end{array}$ \\
\hline ... from IA 93 & 56 & 0.393 & 0.536 & $\begin{array}{c}-0.286^{* *} \\
(0.127)\end{array}$ \\
\hline
\end{tabular}

The table presents the attrition rate at the school level. For each attrition measure, I provide the number of observations $(N)$, the average attrition rate (Sample average), the average in the control group $(C)$ and the difference between the treatment and the control group $(T-C)$. Robust standard errors of the coefficients are given in parentheses.

${ }^{*} \mathrm{p}<0.1,{ }^{* *} \mathrm{p}<0.05,{ }^{* * *} \mathrm{p}<0.01$. 
In Table 2, I use the few school-level variables available ${ }^{21}$ and some socioeconomic data from neighborhoods to investigate further how attrition may affect the estimation. ${ }^{22}$ In Panel A, I describe the schools included in the original 118 schools sample. The schools selected for this experiment were primarily from poor neighborhoods; the original sample is composed of a large proportion of schools in priority education, $59 \%$ (resp. $37 \%$ in RAR), while the national average is $17.9 \%$ (resp. 6.3\%) (DEPP (2010)). Schools are also situated in disadvantaged neighborhoods: unemployment is high at $12.6 \%$ (compared to $7.8 \%$ in the total population), and the share of immigrants is much higher than the rest of the population (21.6\% versus $6.2 \%$ in the total population). This corresponds with the desired objective to implement the new methodology in the poorest schools. Not surprisingly at that stage, there are no differences between treatment and control schools, as size, location, and priority education were used to stratify the sample. Other variables not used for stratification are also very well balanced.

In Panel B, I look at the same characteristics after the first wave of attrition (before baseline), allegedly the most worrisome analytically. Average results in the control group and differences between treatment and control group are not affected significantly by attrition before baseline. The same conclusion applies to Panel C where I look at the sample that have replied to the endline survey.

\footnotetext{
${ }^{21}$ Unlike primary schools or secondary schools, data at kindergarten level are scarce in France.

${ }^{22}$ Data from the National Institute of Statistics using IRIS zone.
} 


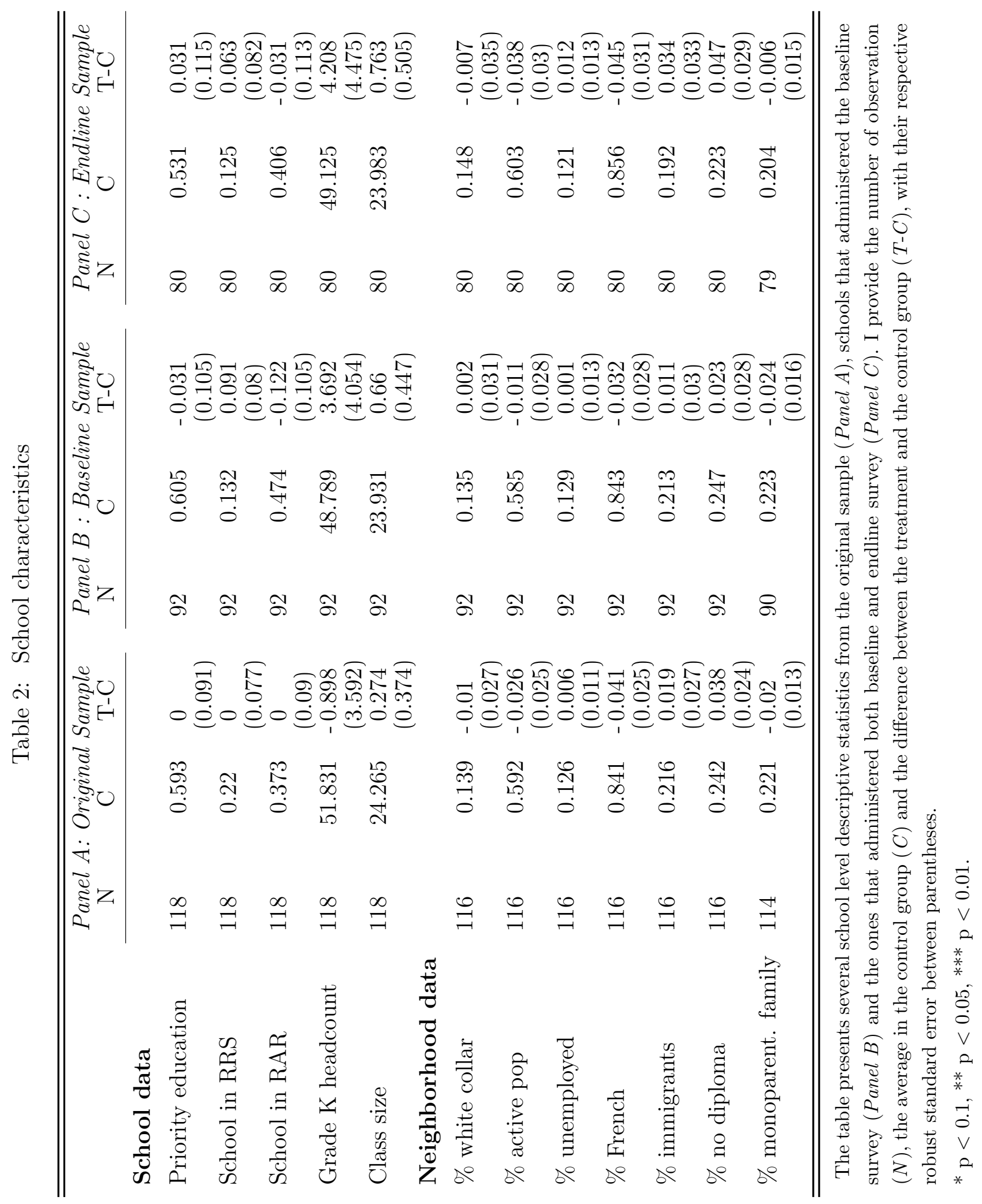




\subsection{Teacher-Level Data}

To obtain additional information besidesschool characteristics, a teacher questionnaire was sent to all teachers who benefited from the training program. In order to have a point of comparison, the same questionnaire was also sent to control schools. Unfortunately, lack of political support rendered surveying control schools in IA 93 and 59 difficult. In both IAs, therefore, the response rate was significantly lower and highly differential. Generally speaking, surveying teachers in France is a difficult task.23 Teachers rarely agree to give their names in surveys and they do not readily answer questionnaires, as they and their unions often fear that such data would be used for evaluating their individual performances. Furthermore, school administration is often reluctant to communicate teacher-level information. As a result, response rate is not satisfactory: sometimes teachers refused to communicate the names of their children, sometimes they refused to communicate their own names, and sometimes they simply neglected to return the questionnaire at all ${ }^{24}$

On the full sample, results are undermined by a high and differential attrition level (a significant -21.6\%). Hence, results should be interpreted with care. Yet it seems that teachers in the treatment group are significantly older and more experienced than those in the control group. Point estimates suggest that treatment teachers have on average 3.6 years of experience and are 3.6 years older. To a lesser extent, treatment teachers appear to have more experience in kindergarten. Besides, teachers in the treatment group have a lower attainment of higher education (-0.6 years). As the minimum requirements to become an elementary teacher have increased during the last 30 years in France, both results are potentially related. Yet when I condition by birth year, higher education attainment remains negative and significant (-0.53 years). Treatment teachers are also significantly more likely to have studied a hard science discipline and less likely to have studied humanities (all subjects). This might be indicative of selection, as scientific studies allegedly attract better students. Finally, in terms of job status, both groups are relatively comparable: teachers are usually full time (permanent), and the vast majority work in only one

\footnotetext{
${ }^{23}$ For instance, France is one of the rare OECD countries that refused to administer the PISA teacher questionnaire (TALIS) the first year.

${ }^{24}$ For the cases where I received a questionnaire but either the teacher's name or the classroom number was missing, I simply averaged the results obtained by the teacher(s) and apply the result(s) to all GS children enrolled in the school. In subsequent models using teacher characteristics, I will always control for a dummy, indicating whether such procedure was implemented. In Table 3, I present the results from the teacher survey both on the original sample and on the sample of schools from IA 92 and 62 , where the control group was more willing to participate in the survey.
} 
school (they are not substitutes). Interestingly, treatment teachers are less likely to work in mixed-level classes (classes composed of children from different grades) ${ }^{25}$ As the training program was specifically designed for the last year of kindergarten, treatment schools may have decided to exclude mixed classes from the program.

I also present in Table 3 some information on the teacher practices. I first look at the amount of hours spent on literacy and non-literacy subjects. Although treatment teachers tend to spend less time on non-literacy subjects, they do not report spending more time on literacy subjects. More convincing are the variables about the way teaching was structured in treatment schools: treatment teachers report working more systematically with small groups of students of the same initial achievement level (tracked small groups) and are significantly more likely to use only one reading method. Results suggest that the program has not modified the amount of literacy provided, but has probably more significantly modified the way literacy classes were given: in small groups, formed by initial achievement level, and using solely one method (certainly the one provided by the NGO). The fact that they are more likely to use only one method could be interpreted as a sign that teachers partly gave up on the principle of "liberté pédagogique" (freedom to teach) that allow them to use whichever method they want and sometimes mixing several approaches. ${ }^{26}$

Results from the sub-sample composed of schools from IA 92 and IA 62, for which attrition is lower and not significantly differentia 27 , confirmed and even amplified the findings. Teachers are on average four years older in the treatment group; they are more experienced (four additional years), and have more years of experiences in kindergarten. Similarly to the results obtained on the full sample, treatment teachers have spent fewer years in higher education and are more likely to be from a hard science background and less likely from a humanities background.

\footnotetext{
${ }^{25}$ When the preschool is attached to a primary school, grade 1 and GS students are usually mixed together, as they belong to the same teaching "cycle"; otherwise, GS can be mixed with MS, or "Moyenne Section" ( $4-5$ years old).

${ }^{26}$ The prior of the NGO is that teachers would use several methodological approach, mix them, often in a very inconsistent way

${ }^{27}$ Since detection power is low and differential attrition is not significantly different on the sub-sample and full sample, absence of significance at this level should be interpreted with caution.
} 
Table 3: Teacher questionnaire: Descriptive statistics

\begin{tabular}{|c|c|c|c|c|c|c|c|c|}
\hline & \multicolumn{4}{|c|}{ Panel A: Full Sample } & \multicolumn{4}{|c|}{ Panel B: IA 92 and 62 } \\
\hline & $\mathrm{N}$ & Average & $\mathrm{C}$ & $\mathrm{T}-\mathrm{C}$ & $\mathrm{N}$ & Average & $\mathrm{C}$ & $\mathrm{T}-\mathrm{C}$ \\
\hline Attrition & 147 & 0.565 & 0.676 & $\begin{array}{l}-0.216^{* * *} \\
(0.08)\end{array}$ & 70 & 0.243 & 0.268 & $\begin{array}{c}-0.157 \\
(0.103)\end{array}$ \\
\hline \multicolumn{9}{|l|}{ Teachers' experience } \\
\hline Birth year & 60 & 1972.433 & 1974.696 & $\begin{array}{c}-3.669^{*} \\
(1.875)\end{array}$ & 52 & 1972.365 & 1973.5 & $\begin{array}{c}-4.178^{* *} \\
(1.949)\end{array}$ \\
\hline Teaching experience & 62 & 13.666 & 11.374 & $\begin{array}{c}3.644^{*} \\
(1.977)\end{array}$ & 53 & 13.798 & 13.256 & $\begin{array}{c}4.282^{*} \\
(2.145)\end{array}$ \\
\hline Preschool experience & 61 & 11.101 & 9.255 & $\begin{array}{c}2.889 \\
(1.831)\end{array}$ & 52 & 11.484 & 10.817 & $\begin{array}{c}3.865^{*} \\
(1.982)\end{array}$ \\
\hline \multicolumn{9}{|l|}{ Teachers' education } \\
\hline Higher education level & 62 & 3.355 & 3.739 & $\begin{array}{c}-0.611^{* *} \\
(0.278)\end{array}$ & 53 & 3.34 & 3.533 & $\begin{array}{c}-0.706^{* *} \\
(0.313)\end{array}$ \\
\hline Arts degree & 60 & 0.4 & 0.591 & $\begin{array}{l}-0.301^{* *} \\
(0.13)\end{array}$ & 51 & 0.431 & 0.552 & $\begin{array}{l}-0.281^{* *} \\
(0.138)\end{array}$ \\
\hline Hard science degree & 60 & 0.2 & 0.091 & $\begin{array}{c}0.172^{*} \\
(0.096)\end{array}$ & 51 & 0.196 & 0.207 & $\begin{array}{c}0.185^{*} \\
(0.105)\end{array}$ \\
\hline Other degree & 60 & 0.4 & 0.318 & $\begin{array}{c}0.129 \\
(0.13)\end{array}$ & 51 & 0.373 & 0.241 & $\begin{array}{c}0.096 \\
(0.138)\end{array}$ \\
\hline \multicolumn{9}{|l|}{ Teachers' status } \\
\hline Full-time teacher & 64 & 0.906 & 0.957 & $\begin{array}{c}-0.078 \\
(0.068)\end{array}$ & 53 & 0.925 & 0.967 & $\begin{array}{c}-0.057 \\
(0.071)\end{array}$ \\
\hline Teach in 1 school & 64 & 0.891 & 0.913 & $\begin{array}{c}-0.035 \\
(0.079)\end{array}$ & 53 & 0.906 & 0.933 & $\begin{array}{c}-0.013 \\
(0.082)\end{array}$ \\
\hline Mixed-level class & 64 & 0.266 & 0.435 & $\begin{array}{c}-0.264^{* *} \\
(0.121)\end{array}$ & 53 & 0.264 & 0.4 & $\begin{array}{c}-0.301^{* *} \\
(0.123)\end{array}$ \\
\hline \multicolumn{9}{|l|}{ Teachers' practices } \\
\hline Literacy hours & 49 & 6.015 & 6.075 & $\begin{array}{c}-0.101 \\
(0.981)\end{array}$ & 41 & 6.14 & 6.022 & $\begin{array}{c}0.127 \\
(1.067)\end{array}$ \\
\hline Non-literacy hours & 50 & 3.303 & 3.497 & $\begin{array}{c}-0.323 \\
(0.197)\end{array}$ & 42 & 3.265 & 3.456 & $\begin{array}{l}-0.442^{* *} \\
(0.21)\end{array}$ \\
\hline Non-tracked groups & 54 & 2.685 & 3.087 & $\begin{array}{c}-0.7^{* *} \\
(0.271)\end{array}$ & 46 & 2.652 & 2.926 & $\begin{array}{c}-0.87^{* * *} \\
(0.294)\end{array}$ \\
\hline Tracked groups & 56 & 3.196 & 2.455 & $\begin{array}{l}1.222^{* * *} \\
(0.204)\end{array}$ & 48 & 3.104 & 2.63 & $\begin{array}{l}1.199^{* * *} \\
(0.213)\end{array}$ \\
\hline Only 1 method & 52 & 2.308 & 1.6 & $\begin{array}{l}1.15^{* * *} \\
(0.286)\end{array}$ & 44 & 2.25 & 1.76 & $\begin{array}{l}1.192^{* * *} \\
(0.303)\end{array}$ \\
\hline
\end{tabular}

The table presents some teacher descriptive statistics for two panels (full sample and districts 92 and 62). The table gives the number of observation, the average in the sample (Sample average) and in the control (Control average) and the differences bewteen treatment and control teachers $(T-C)$. For each dependant variable, the number of observations $(\mathrm{Obs})$, the sample average, the average in the control group and the difference between the treatment and the control group (Coef) are provided with their respective robust standard error below between parentheses.

${ }^{*} \mathrm{p}<0.1,{ }^{* *} \mathrm{p}<0.05,{ }^{* * *} \mathrm{p}<0.01$. 
The literature usually suggests that observable characteristics are not very predictive of teacher effect. Yet, among the various studies about teacher effect, years of experience were reported to be the most predictive. In the most recent work on this topic, Harris and Sass (2011) find for instance that, in elementary school, each year of experience is associated with approximately $0.65 \%$ of a standard deviation increase in reading skills. To verify whether such a relationship is present here, I look at the correlation between teachers' characteristics and follow-up test scores, controlling for baseline test scores and some individual characteristics. Results are presented in Table 4.

Given the small sample size and the classroom-level clustering, I lack statistical power to precisely identify the effect. ${ }^{28}$ Some suggestive correlations, however, can be significantly identified. Teaching experience is, for instance, estimated to have a positive effect of $0.6 \%$ to $1 \%$ per year. This is very close to the estimation found by Harris and Sass (2011) (0.65\% per year of experience) ${ }^{29}$ Taken linearly at face value, this rough estimate would translate into a .20 to .33 s.d. difference between the youngest teacher (0 years of experience) and the oldest teacher in my sample (33 years of experience). I then look at the effect previous education track on pupil progression. I divide degrees into three groups: arts, hard science, and others 40 I find that art and hard science degrees outperform other degrees by a significant $15 \%$ s.d., with art and hard science effect being similar most of the time. The coefficient for higher education level (attainment) is also significant. Since teachers in the treatment group are both more experienced but less educated and less likely to have specialized in arts, it is uncertain in which direction a teacher selection bias would go. Further investigations on the impact of teacher effect will be undertaken in Section 7 .

\footnotetext{
${ }^{28}$ Note that Harris and Sass (2011) do not cluster at the teacher level, but use the panel structure of their dataset by adding a teacher fixed effect.

${ }^{29}$ In fact, Harris and Sass estimate a more flexible model allowing for a nonlinear impact of experience. They find, for instance, that after 15-24 years of experience, teachers have a value-added effect of .13 standard deviation above teachers with no experience, which translates to a rough linear effect of $.13 / 20=$ $6.5 \%$ per year of experience. Due to the small sample size, my dataset does not allow a similar non-linear estimation.

${ }^{30}$ Others are grouped into all field not included in art and hard science: political science, law, vocational training, computer science, and so forth.
} 
Table 4: Correlation between teacher characteristics and their value-added

\begin{tabular}{lccccc}
\hline \hline & Vocab & Letter & Comp & Phono & Global \\
\hline Teaching experience & 0.009 & $0.006^{* *}$ & 0.007 & 0.010 & $0.006^{*}$ \\
& $(0.006)$ & $(0.003)$ & $(0.005)$ & $(0.007)$ & $(0.003)$ \\
Higher education attainement & $0.111^{* * *}$ & 0.025 & $0.058^{*}$ & $0.068^{*}$ & $0.055^{* * *}$ \\
& $(0.028)$ & $(0.018)$ & $(0.032)$ & $(0.039)$ & $(0.020)$ \\
Non-education experience & -0.087 & $-0.174^{* * *}$ & 0.047 & -0.091 & -0.085 \\
& $(0.110)$ & $(0.053)$ & $(0.116)$ & $(0.173)$ & $(0.055)$ \\
Higher education track & & & & & \\
$\ldots$ hard science & 0.110 & $0.194^{* * *}$ & 0.016 & 0.170 & 0.087 \\
& $(0.103)$ & $(0.064)$ & $(0.083)$ & $(0.151)$ & $(0.058)$ \\
... Arts & $0.193^{* *}$ & $0.119^{* *}$ & $0.309^{* * *}$ & 0.032 & $0.123^{* *}$ \\
& $(0.078)$ & $(0.052)$ & $(0.105)$ & $(0.133)$ & $(0.054)$ \\
$\ldots$ other degree & & & & & \\
\hline Observations & 1374 & 1370 & 1349 & 1312 & 1417 \\
$\mathrm{R}^{2}$ & 0.365 & 0.374 & 0.342 & 0.287 & 0.531 \\
\hline \hline
\end{tabular}

The table presents the correlation between follow-up test scores and some teacher characteristics. Regressions are controlled for the treatment variable, the baseline scores, and whether or not the teacher characteristics were exactly matched with the teacher class. Standard errors are robust and account for intra-classroom correlation.

${ }^{*} \mathrm{p}<0.1,{ }^{* *} \mathrm{p}<0.05,{ }^{* * *} \mathrm{p}<0.01$.

\subsection{Learner-Level Data}

Most data were collected at the pupil level. A first survey (baseline) was administered at the beginning of the GS year (November 2011), followed by a similar survey (follow-up) at the end of GS (June 2012). The intervention started after baseline, between December 2011 and January 2012: the data hence allow measure the effect of a 6 months intervention. Tests were specifically designed by educational specialist ${ }^{31}$ to cover all literacy skills supposed to be mastered by the end of kindergarten: letter recognition, vocabulary, sounds recognition, comprehension. At follow-up, decoding ("pseudo reading") and reading scores were also included, although this is not part of the official GS curriculum. Tests were internally invigilated (by the GS teacher) but externally marked.

\footnotetext{
31"Laboratoire d'Etudes des Mécanimes Cognitifs", "Apprentissage, Développement et Troubles du Langage" group, University Lumière Lyon 2.
} 


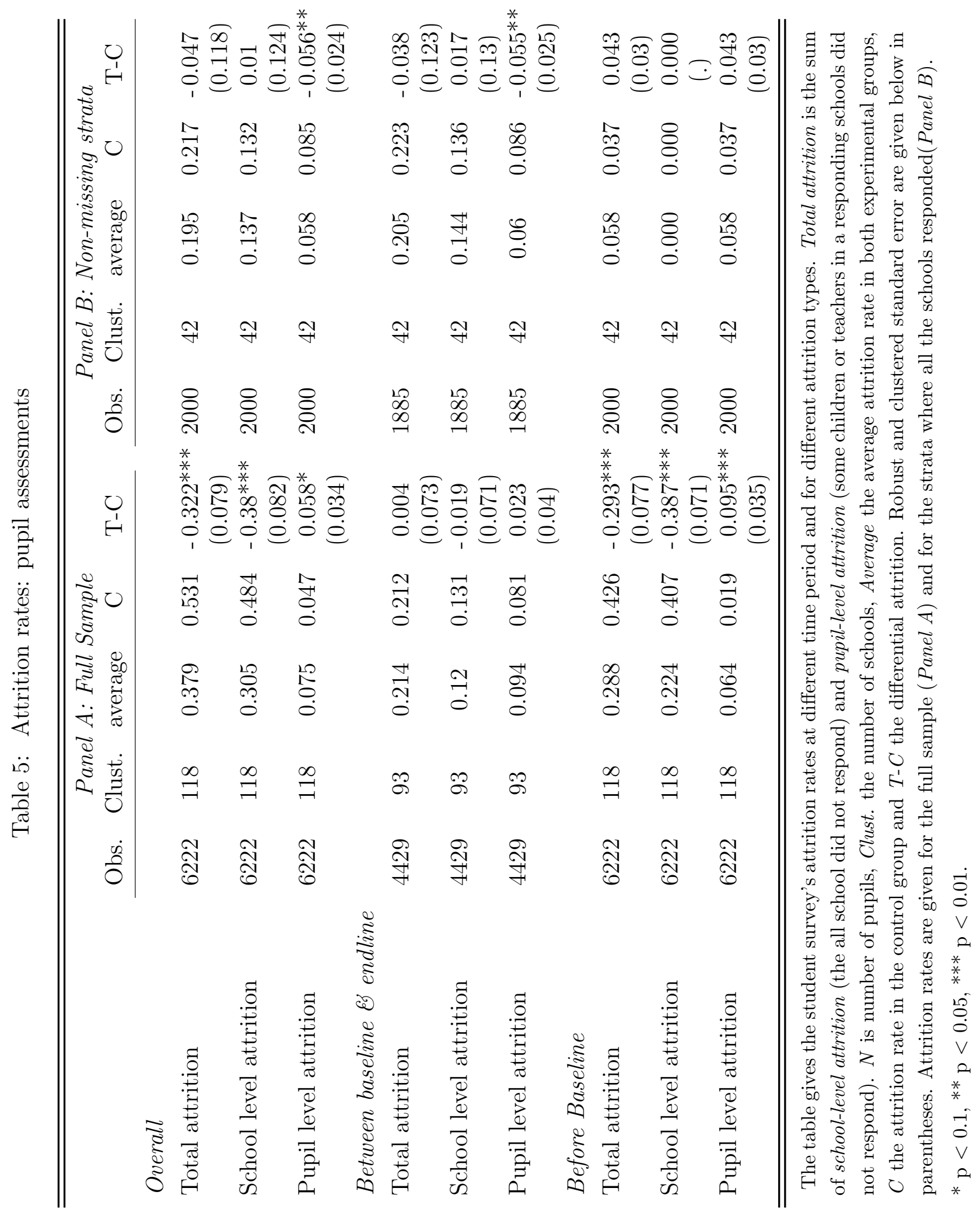


Panel A of Table 5 describes the rate of response obtained from the pupil survey. Taken together and on the full sample (first 3 rows), overall attrition (the child has not responded to either baseline or follow-up) is high ( $38 \%$ from the original sample of 6222 students and 118 schools) and significantly different in control and treatment (-32\%). As mentioned before, school-level attrition (the whole school refused to respond) fully drives down the response rates. This illustrates the fact that in many instances, schools - more systematically, control schools - refused to administer the tests. More surprising is the $+5.8 \%$ significant effect for pupil's attrition (the school responded but not the pupil). Although one could imagine that the teachers in the treatment schools might have been more motivated to have every child present for the test, this is probably not the most probable explanation 32 Rather, in control schools that accepted to participate in the evaluation, it is probable that some teachers refused to administer the tests.

Then, I decompose "overall attrition" into attrition before baseline and between baseline and follow-up. Although attrition remains important between baseline and follow-up, at that stage, attrition is not differential, suggesting that when schools accepted the protocol, the intervention did not change their response behavior. Hence, attrition between baseline and follow-up is less likely to pose an analytic threat. More worrisome is attrition before baseline (between the sample formation and the baseline assessment), which is high $(28.8 \%)$, still driven by attrition at school level (22.4\%), and strongly differential (-29\% in total, $-38.7 \%$ from schools). On the full sample, attrition poses a real threat to analysis. 33

One way to circumvent the attrition issue is to compare similar respondent schools (composed of supposedly more similar teachers), using the way the sample was formed before baseline. As said, to select the control schools, 24 strata were formed based on district location, school size, and priority education level. For each treatment school included in a strata, one control school was randomly selected. Treatment and control schools included in the same strata are allegedly more comparable, especially if the variables used for stratification are predictive of the school/teacher effect. As a result, it is interesting to look at the results obtained on the strata in which no schools have dropped before baseline (10 strata out of 24). Results for this sub-sample are presented in Panel B.

\footnotetext{
${ }^{32}$ I doubt teachers would have sufficient leverage to convince parents to send their children to school on that day.

${ }^{33}$ Note that while downward bias is more credible as complier schools and teachers are more likely to be better performing, an upward bias cannot be ruled out.
} 
By definition in Panel B, attrition rate at school level "before baseline" is 0, and total attrition remains small and not significantly different in the treatment and control group. Although some pupil level attrition has occurred between baseline and follow-up, the overall differential attrition is reduced to a nonsignificant $-4.7 \%$. Panel $\mathrm{B}$ sample is hence a credible sample to estimate the treatment effect purified from most teacher/school selection due to attrition.

Interesting as well are the results obtained in both experimental groups at baseline and follow-up as displayed in Table 6. In Panel A, I look at the results obtained at baseline and follow-up on test scores on the full sample. At baseline, the treatment group underperformed significantly compared to the control group (around a quarter of a standard deviation below). Since both groups were not formed randomly, initial disequilibrium may be contingent, and should not pose an analytical problem as long as the VAM's assumptions mentioned in Section 2 are met. Yet it may also be indicative of selection at the teacher or the school level. For instance, if the district managers have chosen the traditionally poorer performing schools (composed of the least performing teachers) to implement the program in their district (and if stratification did not control for this selection), estimation results should be biased. If selection has occurred, treatment effect should be a priori biased toward zero. Overestimation of the treatment effect would only be possible if district managers have chosen the schools composed of both low performing students but good performing teachers. This would be at odds with some previous results regarding the way teachers are allocated in France 34 Attrition before baseline, as documented previously, may also account for the differences in initial performance. For instance, if the least performing control schools dropped out from the sample before baseline, the population of respondent control schools would obtain better results. Again, downward bias is more credible here. If one assumes no teacher or school selection, the study is, in fact, in a relatively favorable situation. As mentioned in Section 2, when no selection occurs at the teacher or school level, the sign of the VAM1 bias is fully determined by $r\left(A_{0}, T\right)$, the initial group's equilibrium. Since the treatment group's students initially under-perform versus the controls, the VAM1 should give a downward biased estimate of the true treatment effect.

More interesting at that point are the results obtained on the students in schools not affected by baseline attrition (non-missing strata). This subsample, which is allegedly less

\footnotetext{
${ }^{34}$ See Bressoux et al. (2009), where they suggest that more experienced teachers are assigned to better performing schools in France.
} 
affected by attrition bias, is highly comparable to the full sample. Column $\mathrm{C}$ of Panel $\mathrm{B}$ shows that results of the control group are almost similar in both panels 35

At endline, the treatment group seems to have caught up with the control group in the full sample and in the sample composed of strata without missing schools in a similar fashion: naive difference-in-differences estimates ("T-C" columns) give comparable effect sizes in both samples. To give statistical weight to this assertion, I compare in column "A-B Panel" the naive difference-in-differences estimate. They are all near zero and never significant.

\footnotetext{
${ }^{35}$ Results are standardized using the standard deviation of the control group; hence, the control group estimates on the non missing strata sub-sample indicates the difference between the full sample and this sub-sample. For instance, on the sub-sample, control children in panel B outperform the full sample by a nonsignificant $1.8 \%$ of a standard deviation.
} 
Table 6: Pupil's test score at baseline and endline results: simple comparison

\begin{tabular}{|c|c|c|c|c|c|c|c|c|c|}
\hline & \multicolumn{4}{|c|}{ Panel A: Full Sample } & \multicolumn{4}{|c|}{ Panel B: Non-missing strata } & \multirow[b]{2}{*}{ A-B pane } \\
\hline & $\mathrm{N}$ & Clust. & $\mathrm{C}$ & $\mathrm{T}-\mathrm{C}$ & $\mathrm{N}$ & Clust. & $\mathrm{C}$ & $\mathrm{T}-\mathrm{C}$ & \\
\hline Baseline & & & & & & & & & \\
\hline Vocabulary & 4345 & 93 & 0 & $\begin{array}{c}-0.245^{* *} \\
(0.097)\end{array}$ & 1833 & 42 & 0.018 & $\begin{array}{c}-0.282 \\
(0.181)\end{array}$ & $\begin{array}{c}0.068 \\
(0.217)\end{array}$ \\
\hline Letter recognition & 4330 & 93 & 0 & $\begin{array}{c}-0.183^{* *} \\
(0.072)\end{array}$ & 1835 & 42 & 0.041 & $\begin{array}{c}-0.151 \\
(0.108)\end{array}$ & $\begin{array}{c}-0.023 \\
(0.142)\end{array}$ \\
\hline Comprehension & 4280 & 93 & 0 & $\begin{array}{c}-0.075 \\
(0.087)\end{array}$ & 1799 & 42 & -0.058 & $\begin{array}{c}-0.108 \\
(0.12)\end{array}$ & $\begin{array}{c}0.013 \\
(0.17)\end{array}$ \\
\hline Phonology & 4139 & 92 & 0 & $\begin{array}{c}-0.332^{* * *} \\
(0.094)\end{array}$ & 1711 & 41 & 0.011 & $\begin{array}{c}-0.347^{* *} \\
(0.145)\end{array}$ & $\begin{array}{c}0.028 \\
(0.196)\end{array}$ \\
\hline Endline & & & & & & & & & \\
\hline Vocabulary & 3781 & 82 & 0 & $\begin{array}{c}-0.171 \\
(0.116)\end{array}$ & 1562 & 36 & -0.007 & $\begin{array}{c}-0.288 \\
(0.225)\end{array}$ & $\begin{array}{c}0.172 \\
(0.269)\end{array}$ \\
\hline Letter recognition & 3744 & 81 & 0 & $\begin{array}{c}0.033 \\
(0.06)\end{array}$ & 1524 & 35 & 0.008 & $\begin{array}{c}0.017 \\
(0.099)\end{array}$ & $\begin{array}{c}0.029 \\
(0.127)\end{array}$ \\
\hline Comprehension & 3694 & 81 & 0 & $\begin{array}{c}0.003 \\
(0.104)\end{array}$ & 1509 & 35 & -0.102 & $\begin{array}{c}0.085 \\
(0.152)\end{array}$ & $\begin{array}{c}-0.188 \\
(0.205)\end{array}$ \\
\hline Phonology & 3643 & 81 & 0 & $\begin{array}{c}0.056 \\
(0.097)\end{array}$ & 1487 & 35 & -0.039 & $\begin{array}{c}0.078 \\
(0.156)\end{array}$ & $\begin{array}{l}-0.06 \\
(0.199)\end{array}$ \\
\hline Pseudo reading & 3637 & 81 & 0 & $\begin{array}{l}0.245^{* * *} \\
(0.08)\end{array}$ & 1495 & 35 & 0.027 & $\begin{array}{c}0.198 \\
(0.139)\end{array}$ & \\
\hline Lexical reading & 3611 & 81 & 0 & $\begin{array}{c}-0.049 \\
(0.074)\end{array}$ & 1500 & 35 & 0.054 & $\begin{array}{c}-0.074 \\
(0.109)\end{array}$ & \\
\hline Reading & 3722 & 81 & -0.005 & $\begin{array}{c}0.097 \\
(0.073)\end{array}$ & 1532 & 35 & 0.037 & $\begin{array}{c}0.057 \\
(0.116)\end{array}$ & \\
\hline
\end{tabular}

The table gives the results from the baseline and endline pupil survey, for the full sample and the sample composed of the strata without missing schools (Non-missing strata). T-C represents the simple comparison between the treatment and the control group at baseline (first rows) and at endline (last rows). I give the number of pupils $(N)$, the number of schools (Clust), the control average $(C)$. T-C's standard errors are robust and clustered at school level. Under columns $A$-B panel, I compare the T-C coeficients of both panels. Scores are standardized using the standard deviation of the control group.

$* \mathrm{p}<0.1,{ }^{* *} \mathrm{p}<0.05,{ }^{* * *} \mathrm{p}<0.01$. 
In all, I have no reason to believe that the non-missing strata sample is significantly different from the full sample. It presents no different baseline test scores and is comparable in terms of school level characteristics (results not displayed here). Unfortunately, I am not able to provide a similar argument for teacher-level characteristics, as the schools that did not drop out are not necessarily composed of teachers who responded to the teacher questionnaire. I am here facing one limitation of my data: I can either deal with attrition or teacher-level selection, but not both at the same time. Fortunately, results are quite consistent whatever strategy is used.

\section{Results}

\subsection{Comparing Value-Added Models}

I first present in Table 7 the results from both value added models presented in Section 2 , using the competences that were tested at both baseline and follow-up. Results from VAM1 are generally positive and significant for competences that were primarily stimulated by the new pedagogy (i.e., phonology and letter recognition). Results are closer to zero for competences not directly related to the treatment (vocabulary and comprehension). These results have both a positive and negative side. On the one hand, the fact that not all competences were improved suggests that results are not fully driven by selection at the teacher, school or parent level, as such selection would have affected positively all competences indistinctly. On the other, it suggests that the effect on competences directly targeted by the program had not translated into indirect improvement on other very important competences for literacy (vocabulary and comprehension). 


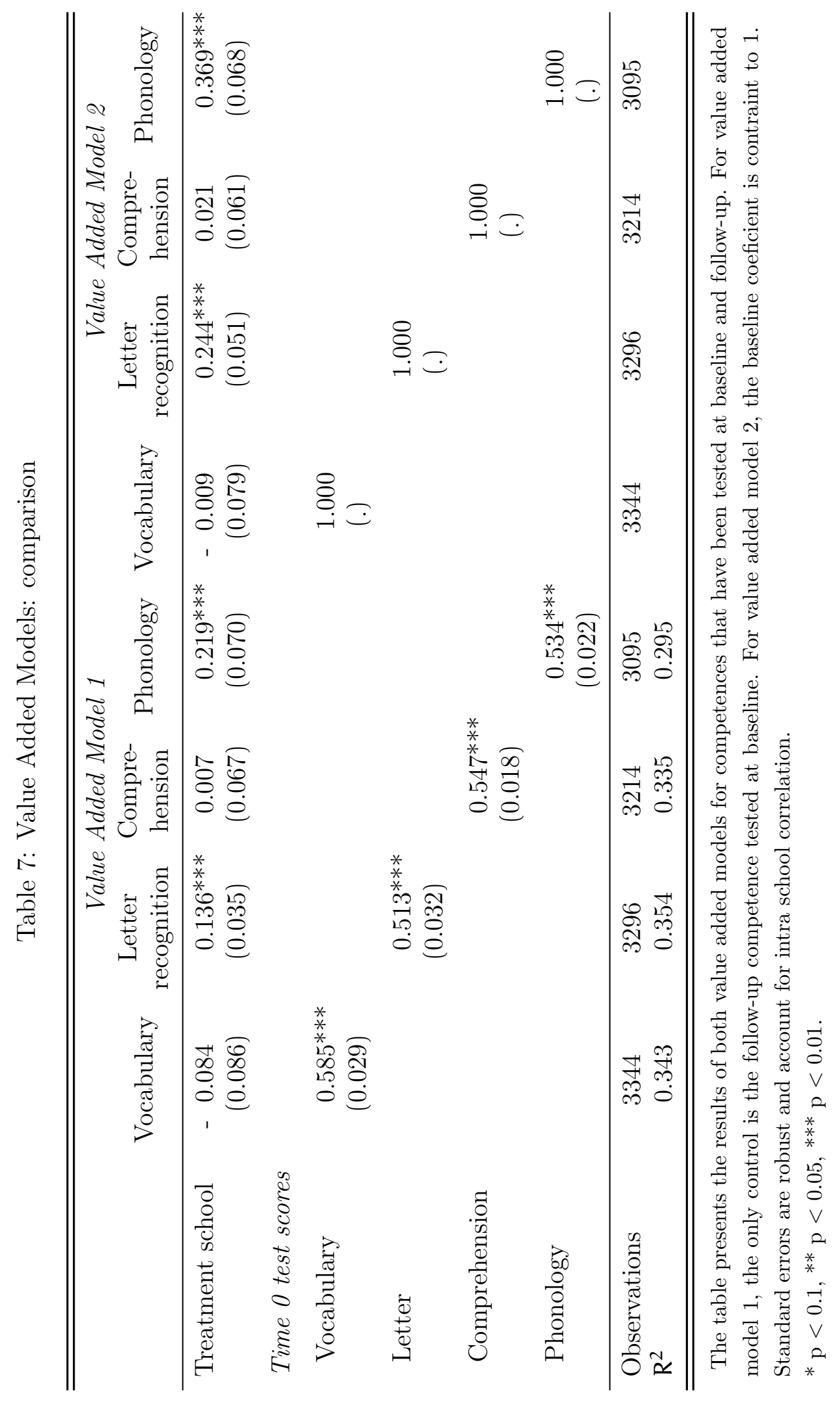


As predicted in 2, because $\gamma$ is below 1 and treatment students were initially weaker, VAM1 is a lower bound and hence is lower than the VAM2. Besides, $\hat{\gamma}$ s are far below from 1 (around .5), suggesting that $\rho$ s are likely to be below 0, and hence, the underlying progression model is suggested to be convergent ${ }^{36}$ This is in line with what one may intuitively think about child development: the initial gap in early reading skills is expected to be filled (at least partly) when reading lessons start.

\subsection{Pupil-Level Characteristics Estimates}

To improve my estimation, I add in Table 8 several additional baseline characteristics to the value added model 1 (quarter of birth, gender, and whether or not the child has a foreign-sounding first name), and I control for a full set of baseline test scores. I also add as co-variate the average within classroom of the baseline global test score ("peer effect"): I intend to capture the effect of being enrolled in a classroom with higher-performing peers. ${ }^{37}$ I finally estimate the effect on dimensions that were not evaluated at baseline: pseudo reading (decoding, reading of nonlexical words) and lexical reading (ability to read actual words, a skill that is not supposed to be mastered at that age). (12).

Results are consistently positive and significant for the dimensions most directly stimulated by the training program: segmentation and sounds recognition (later regrouped into a phonology index) are, for instance, positive and significant (.18 s.d. and .24 s.d.), while comprehension and vocabulary are unaffected. The strongest effect is found on the "Pseudo-reading" competence, whose effect is particularly large (.45 s.d.). Point estimate for the lexical reading score is smaller but remains significant ${ }^{38}$ Besides, I can relatively precisely detect a significant effect of $13.5 \%$ standard deviation on letter recognition skills, a competence only indirectly covered by the training program ${ }^{39}$ Finally, correlation between baseline variables and follow-up test score suggests that letter recognition and phonology competences (segmentation and sounds recognition) are the most predictive competences

\footnotetext{
${ }^{36}$ As said, $\hat{\gamma}$ is biased downward. As a result, the convergence of the model can only be suggested, not proven. The fact that $\hat{\gamma} \mathrm{s}$ are far from 1 indicates, however, that only a large measurement error would make a divergent model credible.

${ }^{37}$ Following Manski (1993), I here estimate the combined endogenous and exogenous peer effect.

${ }^{38}$ Before Grade 1, pupils are not supposed to be readers, and baseline test scores are not good predictors of this competence (lower $\mathrm{R}^{2}$, smaller baseline follow-up correlation)

${ }^{39}$ The letter recognition test consists of identifying the "name" of the letter, not its sound. While the methodology focuses mostly on sounds recognition, it is likely that it indirectly made the pupils familiar with the letters.
} 
Table 8: Value Added Model 1: sub-score results

\begin{tabular}{|c|c|c|c|c|c|c|c|}
\hline & $\begin{array}{c}(1) \\
\text { Voca- } \\
\text { bulary } \quad r\end{array}$ & $\begin{array}{c}(2) \\
\text { Letter } \\
\text { recognition }\end{array}$ & $\begin{array}{c}(3) \\
\text { Compre- } \\
\text { hension }\end{array}$ & $\begin{array}{l}(4) \\
\text { Sounds } \\
\text { recognition }\end{array}$ & $\begin{array}{c}(5) \\
\text { Segmen- } \\
\text { tation }\end{array}$ & $\begin{array}{c}(6) \\
\text { Pseudo } \\
\text { reading }\end{array}$ & $\begin{array}{l}\quad(7) \\
\text { Lexical } \\
\text { reading }\end{array}$ \\
\hline Treatment school & $\begin{array}{c}-0.069 \\
(0.084)\end{array}$ & $\begin{array}{l}0.135^{* * *} \\
(0.033)\end{array}$ & $\begin{array}{c}0.098 \\
(0.062)\end{array}$ & $\begin{array}{l}0.179^{* * *} \\
(0.061)\end{array}$ & $\begin{array}{l}0.244^{\text {*** }} \\
(0.059)\end{array}$ & $\begin{array}{l}0.447^{* * *} \\
(0.063)\end{array}$ & $\begin{array}{c}0.135^{* *} \\
(0.058)\end{array}$ \\
\hline \multicolumn{8}{|l|}{ Baseline test scores } \\
\hline Vocabulary & $\begin{array}{l}0.428^{* * *} \\
(0.034)\end{array}$ & $* \begin{array}{c}0.025 \\
(0.023)\end{array}$ & $\begin{array}{l}0.168^{* * *} \\
(0.023)\end{array}$ & $\begin{array}{l}0.100^{* * *} \\
(0.021)\end{array}$ & $\begin{array}{l}0.138^{* * *} \\
(0.028)\end{array}$ & $\begin{array}{c}0.011 \\
(0.024)\end{array}$ & $\begin{array}{c}0.003 \\
(0.022)\end{array}$ \\
\hline Letter & $\begin{array}{l}0.074^{* * *} \\
(0.020)\end{array}$ & $\begin{array}{l}0.492^{* * *} \\
(0.032)\end{array}$ & $\begin{array}{c}0.018 \\
(0.016)\end{array}$ & $\begin{array}{l}0.150^{* * *} \\
(0.021)\end{array}$ & $\begin{array}{l}0.131^{* * *} \\
(0.017)\end{array}$ & $\begin{array}{l}0.323^{* * *} \\
(0.021)\end{array}$ & $\begin{array}{c}0.162^{* * *} \\
(0.020)\end{array}$ \\
\hline Comprehension & $\begin{array}{l}0.112^{* * *} \\
(0.021)\end{array}$ & $* \begin{array}{c}-0.023 \\
(0.019)\end{array}$ & $\begin{array}{l}0.336^{* * *} \\
(0.019)\end{array}$ & $\begin{array}{l}0.080^{* * *} \\
(0.022)\end{array}$ & $\begin{array}{l}0.126^{\text {*** }} \\
(0.022)\end{array}$ & $\begin{array}{c}0.019 \\
(0.022)\end{array}$ & $\begin{array}{c}0.024 \\
(0.027)\end{array}$ \\
\hline Phonology & $\begin{array}{c}0.031^{*} \\
(0.017)\end{array}$ & $\begin{array}{c}0.027 \\
(0.017)\end{array}$ & $\begin{array}{l}0.124^{* * *} \\
(0.021)\end{array}$ & $\begin{array}{l}0.278^{* * *} \\
(0.023)\end{array}$ & $\begin{array}{l}0.185^{* * *} \\
(0.025)\end{array}$ & $\begin{array}{l}0.255^{* * *} \\
(0.023)\end{array}$ & $\begin{array}{c}0.274^{* * *} \\
(0.029)\end{array}$ \\
\hline \multicolumn{8}{|l|}{ Other covariates } \\
\hline Born 2nd quarter & $\begin{array}{c}-0.065 \\
(0.044)\end{array}$ & $\begin{array}{c}0.010 \\
(0.031)\end{array}$ & $\begin{array}{l}-0.040 \\
(0.040)\end{array}$ & $\begin{array}{c}0.002 \\
(0.039)\end{array}$ & $\begin{array}{c}-0.035 \\
(0.039)\end{array}$ & $\begin{array}{c}0.002 \\
(0.046)\end{array}$ & $\begin{array}{c}-0.003 \\
(0.059)\end{array}$ \\
\hline Born 3rd quarter & $\begin{array}{l}-0.010 \\
(0.065)\end{array}$ & $\begin{array}{c}-0.025 \\
(0.036)\end{array}$ & $\begin{array}{l}-0.124^{* * *} \\
(0.041)\end{array}$ & $\begin{array}{c}-0.076 \\
(0.047)\end{array}$ & $\begin{array}{l}-0.143^{* * *} \\
(0.042)\end{array}$ & $\begin{array}{r}-0.084^{*} \\
(0.045)\end{array}$ & $\begin{array}{c}-0.033 \\
(0.050)\end{array}$ \\
\hline Born 4th quarter & $\begin{array}{c}-0.076 \\
(0.051)\end{array}$ & $\begin{array}{c}-0.029 \\
(0.042)\end{array}$ & $\begin{array}{l}-0.140^{* * *} \\
(0.046)\end{array}$ & $\begin{array}{c}-0.092^{*} \\
(0.051)\end{array}$ & $\begin{array}{c}-0.113^{* *} \\
(0.047)\end{array}$ & $\begin{array}{l}-0.171^{* * *} \\
(0.041)\end{array}$ & $\begin{array}{c}{ }^{*}-0.143^{* * *} \\
(0.047)\end{array}$ \\
\hline Gender $1=$ Male & $\begin{array}{c}-0.053^{*} \\
(0.029)\end{array}$ & $\begin{array}{c}-0.031 \\
(0.025)\end{array}$ & $\begin{array}{c}-0.055^{*} \\
(0.029)\end{array}$ & $\begin{array}{c}-0.040 \\
(0.030)\end{array}$ & $\begin{array}{l}-0.079^{* * *} \\
(0.026)\end{array}$ & $\begin{array}{c}-0.061 * * \\
(0.027)\end{array}$ & $\begin{array}{l}0.071^{* *} \\
(0.032)\end{array}$ \\
\hline Foreign first name & $\begin{array}{c}-0.032 \\
(0.042)\end{array}$ & $\begin{array}{c}-0.011 \\
(0.034)\end{array}$ & $\begin{array}{c}-0.076^{*} \\
(0.040)\end{array}$ & $\begin{array}{c}-0.028 \\
(0.046)\end{array}$ & $\begin{array}{c}-0.046 \\
(0.036)\end{array}$ & $\begin{array}{c}-0.067 \\
(0.049)\end{array}$ & $\begin{array}{c}-0.021 \\
(0.044)\end{array}$ \\
\hline Classroom average & $\begin{array}{c}0.194 \\
(0.127)\end{array}$ & $\begin{array}{c}0.010 \\
(0.063)\end{array}$ & $\begin{array}{l}0.275^{* * *} \\
(0.086)\end{array}$ & $\begin{array}{l}0.344^{* * *} \\
(0.084)\end{array}$ & $\begin{array}{l}0.287^{* * *} \\
(0.092)\end{array}$ & $\begin{array}{l}0.229 * * \\
(0.105)\end{array}$ & $\begin{array}{c}0.186^{*} \\
(0.101)\end{array}$ \\
\hline Observations & 3087 & 3053 & 3012 & 3022 & 3024 & 2977 & 2981 \\
\hline$R^{2}$ & 0.388 & 0.365 & 0.418 & 0.305 & 0.306 & 0.336 & 0.197 \\
\hline
\end{tabular}

The table presents the regression results of time 1 scores (in column) against the treatment variable, time 0 scores and time 0 pupils characteristics. Standard errors are robust and account for intra school correlation.

${ }^{*} \mathrm{p}<0.1,{ }^{* *} \mathrm{p}<0.05,{ }^{* * *} \mathrm{p}<0.01$. 
for reading, while comprehension and vocabulary are barely positively correlated with reading competences. These correlations legitimate the focus given by the training program to phonology, and also suggest that such short-term phonological stimulation will translate into better reading skills at a later stage ${ }^{40}$ As mentioned in section 2 and in appendix A, with additional control variables, the VAM 1 remains a lower bound under assumption 12 . To give empirical credit to this claim, I re-estimate table 8 in the Appendix B, without any control variables: result in table 8 and in the appendix are very similar confirming my predictions.

\subsection{Results by Initial Achievement Level}

One of the expected outcomes of the program is to reinforce the reading skills of the weakest students and prevent their reading difficulty in grade 1. Since pupils were assigned to four tracked groups depending on their initial achievement level, it is natural to split the sample into four groups based on baseline results within schools. Using the VAM1 and keeping the same control variable used in Table 8, I estimate the effect by initial achievement and present the result in Table 9. Results of the control in each group show that the weakest, group 1, is quite significantly delayed (between .4 and .7 standard deviation below the control average), with a large chunk of the distribution (around 15\%) falling even below one standard deviation from the average achievement in the control 41

As expected, the program is particularly effective on the weakest pupils. Impacts on group 1 are strongest on dimensions directly stimulated by the program (letter recognition, segmentation), and the magnitude of the effects tend toward zero as initial achievement improved. The progressive nature of the treatment effect for both dimensions is confirmed when the treatment variable interacts with the group variable ${ }^{42}$ ("TxGroup" column). Likewise, absence of positive treatment effect on comprehension found in Table 8 is nuanced,

\footnotetext{
${ }^{40}$ Incidentally, Table 8 allows to infer a few other interesting relationships. Not surprisingly, maturity matters for cognition, as at the end of the year, students achieve on average around $12 \%$ standard deviation lower than children born at the beginning of the year. Also not surprisingly, boys under-perform girls on most competences. Having a foreign first name is negative, but rarely significant effect, and close to zero. In fact, having a foreign first name is associated with a $15 \%$ s.d. lower performance at baseline, but ability to progress is not significantly affected. Finally, I find strong and significant peer effects: having better-performing peers does influence positively on a student's results.

${ }^{41}$ Such results are consistent with international comparisons where France is often characterized by large achievement inequalities (see the PISA report 2014 for France).

${ }^{42}$ The group variable takes value 1 for the weakest, and 4 for the strongest group.
} 
as the program is quite significantly helpful for the weakest children (+.22 s.d.), a possible consequence of the letter and segmentation's positive effects. Finally, no such heterogeneous effect can be found on reading scores and on sounds recognition, while vocabulary, a dimension not directly stimulated by the program, is never positively affected. These effects are consistent with one of the desired effects of the program, adjusting content to everyone's initial achievement. The weakest children progress faster in skills that arguably constitute the first reading steps (letter recognition and segmentation), while the impact is more "flat" on skills that may benefit more advanced students (nonlexical reading sounds recognition). 


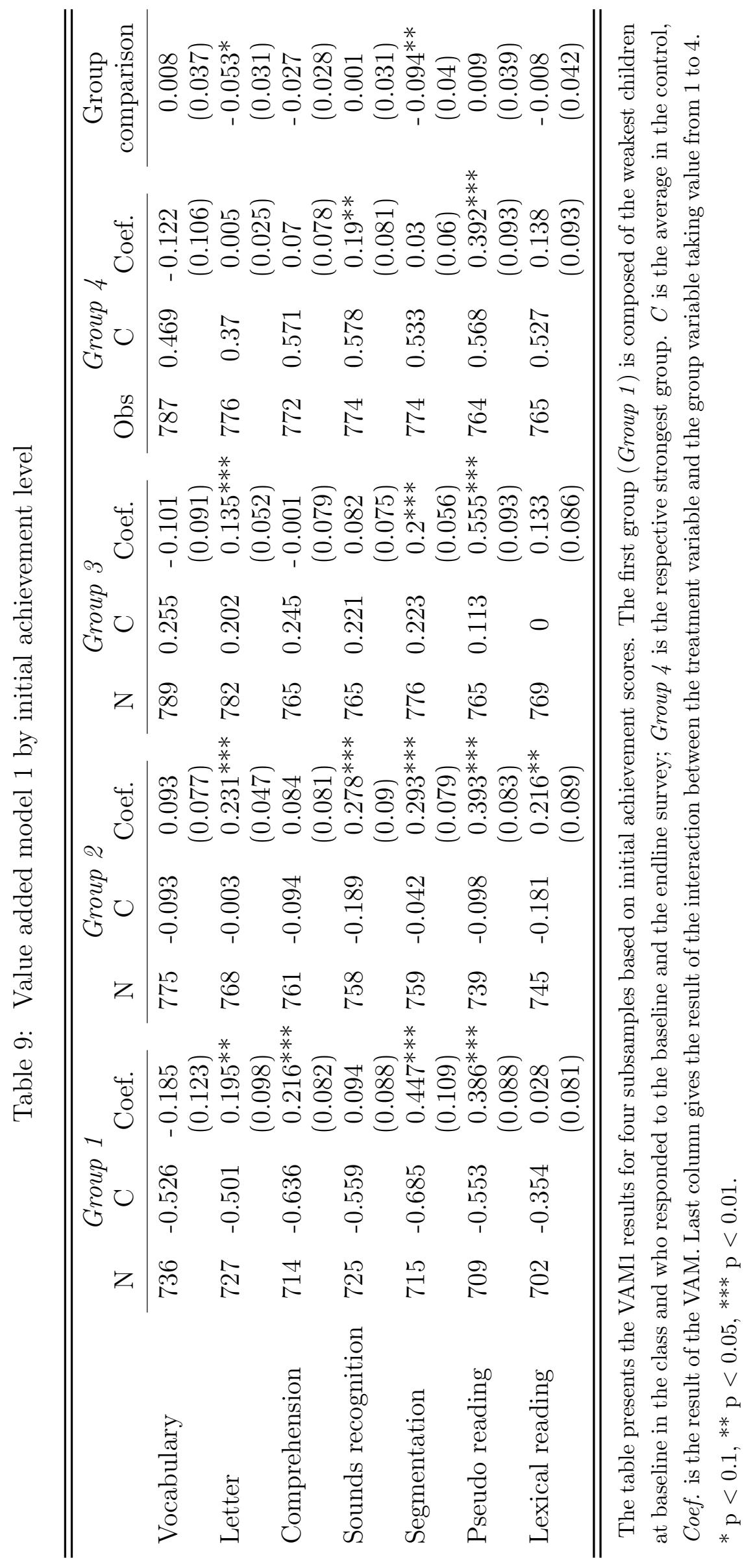




\subsection{Aggregate Measures}

To summarize the results so far, I present in the following table the program's impact on three aggregate indexes. I call "Global" index a summary statistic of all test scores administered at follow-up; the "Reading" index, a summary statistic of both lexical and nonlexical reading score at follow-up; and the "Phonology" index, a summary of segmentation and sound recognition competence. Each index is the average value of their respective treatment effect's sub-scores, estimated using the VAM1. The standard errors are estimated using a Seemingly Unrelated Regression model to account for correlated control variables, as described by Jeffrey R. Kling $(2007)^{43}$. Results are given for the full sample and by initial achievement groups.

Table 10: Treatment effect: Aggregate results

\begin{tabular}{|c|c|c|c|c|c|c|}
\hline & \multicolumn{2}{|c|}{ Global } & \multicolumn{2}{|c|}{ Reading } & \multicolumn{2}{|c|}{ Phonology } \\
\hline & Obs. & Coef. & Obs. & Coef. & Obs. & Coef. \\
\hline Full sample & 3144 & $\begin{array}{l}0.165^{* * *} \\
(0.041)\end{array}$ & 3036 & $\begin{array}{l}0.291^{* * *} \\
(0.056)\end{array}$ & 3060 & $\begin{array}{l}0.211^{* * *} \\
(0.052)\end{array}$ \\
\hline ...Group 1 & 756 & $\begin{array}{l}0.161^{* * *} \\
(0.058)\end{array}$ & 721 & $\begin{array}{l}0.21^{* * *} \\
(0.077)\end{array}$ & 730 & $\begin{array}{l}0.28^{* * *} \\
(0.084)\end{array}$ \\
\hline ...Group 2 & 791 & $\begin{array}{l}0.228^{* * *} \\
(0.042)\end{array}$ & 760 & $\begin{array}{l}0.306^{* * *} \\
(0.07)\end{array}$ & 767 & $\begin{array}{l}0.29^{* * *} \\
(0.068)\end{array}$ \\
\hline ...Group 3 & 802 & $\begin{array}{l}0.147^{* * *} \\
(0.05)\end{array}$ & 782 & $\begin{array}{l}0.343^{* * *} \\
(0.08)\end{array}$ & 783 & $\begin{array}{l}0.142^{* *} \\
(0.055)\end{array}$ \\
\hline ...Group 4 & 795 & $\begin{array}{c}0.107^{*} \\
(0.056)\end{array}$ & 773 & $\begin{array}{l}0.27^{* * *} \\
(0.081)\end{array}$ & 780 & $\begin{array}{c}0.112^{*} \\
(0.063)\end{array}$ \\
\hline
\end{tabular}

The table presents the Seemingly Unrelated Regression results for three aggregate indexes. Overall is an aggregate measure of all sub-scores, Reading a composition of pseudo and lexical reading competences and Phonology an aggregate of sounds recogition and segmentation. Robust and clustered-atschool-level standard errors are displayed in parentheses below the coefficient. Scores are standardized using the standard deviation of the control group.

$* 10 \%$ significance level, ${ }^{* *} 5 \%$ significance level, ${ }^{* * *} 1 \%$ significance level

The Global index has a significant and positive effect of $16.2 \%$ of a standard deviation, while effect sizes are stronger for the reading and phonological summary statistics, respec-

\footnotetext{
${ }^{43}$ I first estimate the standardized treatment coefficients jointly with a seemingly unrelated regression model. I then take the average of these coefficients and the average of their standard error. In absence of a control variable, this procedure is similar to estimating the treatment effect of a global score computed with the standardized version of each test score. With control variables potentially correlated, the global score's coefficients are different and their standard errors are smaller, giving more statistical power.
} 
tively $29 \%$ and $21 \%$. As students' initial achievement increase, the impact on the global index decreases slightly. Yet estimates from the different groups are never significantly different. The pattern is sharper for the Phonology index, where effect size is $27 \%$ for the lowest achievement group and only $11 \%$ for the top group, the difference between both estimates being significant at $10 \%$. On Reading, a competence which is arguably more advanced, such pattern cannot be identified; top groups seem to progress as fast, and even faster, than the low-achieving groups.

Taken together, results from Table 9 and 10 seem to validate a "tracked group" interpretation à la Duflo et al. (2011), where teaching is adjusted more to every student's needs: the training program is here suggested to have homogenized teaching in such a manner that progress was faster on dimensions that were more within the reach of each student. Ultimately in that study as in this one, everyone, weak and strong students alike, benefit from the program.

\section{Dealing with Selection at School or Teacher Level}

As mentioned in Section 2, if $E(v \mid \mathrm{T}) \neq 0$, all results presented so far are potentially biased. This assumption is violated if teachers or schools are systematically different in both experimental groups, either because they were originally different, or because they responded to the survey in a non-random fashion. In the first scenario, the original 118 schools were initially similar (the stratification worked), but schools self-selected out by refusing to participate in the baseline or follow-up survey: a classical case of differential attrition bias. In the second scenario, treatment and control schools, together with their teachers, were initially different. This would occur if, for instance, school district managers have selected treatment schools on unobserved criteria, or schools have volunteered to the program in a non-random fashion. Of course, the most adverse case would be if the best schools were assigned or self-selected into the program, as that would bias upward the estimation 44 In that case, selection may be controlled by appropriate teacher/school level information.

Note that Table 8 provides a first way to look at these threats. Given that the largest effect sizes are found on dimensions directly stimulated by the teacher training program

\footnotetext{
${ }^{44}$ School district managers usually have strong leverage on schools; school directors do not usually decide whether or not to implement a policy. A selection from the school district manager is certainly more likely.
} 
(reading and phonology) and not on others (vocabulary and comprehension), it is unlikely that school or teacher selection have strongly biased the results. If selection has occurred at the school or teacher level, it should indeed have positively affected the vocabulary and comprehension skills of the same magnitude than the other test scores. Besides, since treatment schools were initially weaker than control ones, an upward bias selection would only occur if treatment schools were composed of both weak students and efficient teachers and schools. This is not what one would expect, especially in the French context, where good students tend to be enrolled in schools composed of more experienced teachers 45 Keeping both arguments in mind, I offer the following two additional robustness tests.

\subsection{Dealing with Attrition at the School Level}

As documented in Table 1, control and treatment schools have not responded in a similar fashion to the surveys, a phenomenon which is fully due to differential attrition before baseline 46 Yet, since strata were formed before attrition, on those where no schools dropped out from the sample ("strata without missing schools"), I may be able, under certain conditions analyzed hereafter, to identify the training's impact, cleansed from attrition bias. VAM1 results on the "strata without missing schools" are presented in Table 11.

Results are still positive and significant, notably on competences that matter for literacy. More importantly, they are not systematically different from those found in Table 8: results are smaller for vocabulary, lexical reading, and letter recognition, but higher for comprehension and sounds recognition. Statistically speaking, results are not significantly different in this sub-sample and in the rest of the school, suggesting that attrition has not affected the estimation in a systematic manner. The second "selection" scenario, where "efficient" control schools would have dropped out from the sample before baseline, may not be the most likely one.

Yet there are at least two reasons one may not be fully convinced by this test of robustness. First, one may argue that the results obtained on the "strata without missing schools" concerns peculiar schools (the ones that always respond to surveys) and are hence not externally valid. Baseline results found in 6 tend to suggest otherwise: the schools that belong to these strata have similar characteristics than do the rest of the sample. There

\footnotetext{
${ }^{45}$ see note 33 about on Bressoux et al. (2009)

${ }^{46}$ Note that participating in the program implied only "cost" for control schools as they were not promised any compensatory program, even after the first year of implementation.
} 
Table 11: Value Added Model 1: Sub-score Results, Strata Without Missing Schools

\begin{tabular}{lcccccccc}
\hline \hline & $\begin{array}{c}(1) \\
\text { Voca- } \\
\text { bulary }\end{array}$ & $\begin{array}{c}(2) \\
\text { Letter } \\
\text { recognition }\end{array}$ & $\begin{array}{c}\text { Compre- } \\
\text { hension }\end{array}$ & $\begin{array}{c}(4) \\
\text { Sounds } \\
\text { recognition }\end{array}$ & $\begin{array}{c}(5) \\
\text { Segmen- } \\
\text { tation }\end{array}$ & $\begin{array}{c}(6) \\
\text { Pseudo } \\
\text { reading }\end{array}$ & $\begin{array}{c}(7) \\
\text { Lexical } \\
\text { reading }\end{array}$ \\
\hline Treatment school & -0.124 & $0.115^{* * *}$ & $0.233^{* * *}$ & $0.256^{* * *}$ & $0.309^{* * *}$ & $0.447^{* * *}$ & 0.075 \\
& $(0.161)$ & $(0.041)$ & $(0.071)$ & $(0.074)$ & $(0.096)$ & $(0.080)$ & $(0.072)$ \\
Baseline test scores & & & & & & & \\
Vocabulary & $0.415^{* * *}$ & -0.020 & $0.132^{* * *}$ & $0.104^{* * *}$ & $0.130^{* * *}-0.027$ & 0.012 \\
& $(0.053)$ & $(0.039)$ & $(0.033)$ & $(0.035)$ & $(0.045)$ & $(0.044)$ & $(0.039)$ \\
Letter & $0.098^{* *}$ & $0.535^{* * *}$ & 0.006 & $0.156^{* * *}$ & $0.184^{* * *}$ & $0.330^{* * *}$ & $0.146^{* * *}$ \\
Comprehension & $(0.039)$ & $(0.049)$ & $(0.028)$ & $(0.031)$ & $(0.030)$ & $(0.024)$ & $(0.030)$ \\
& $0.101^{* * *}$ & 0.020 & $0.380^{* * *}$ & $0.077^{* *}$ & $0.138^{* * *}$ & 0.041 & 0.039 \\
Phonology & $(0.031)$ & $(0.024)$ & $(0.032)$ & $(0.033)$ & $(0.036)$ & $(0.039)$ & $(0.040)$ \\
& $0.056^{* *}$ & $0.052^{*}$ & $0.150^{* * *}$ & $0.310^{* * *}$ & $0.215^{* * *}$ & $0.317^{* * *}$ & $0.307^{* * *}$ \\
\hline Observations & $(0.023)$ & $(0.028)$ & $(0.030)$ & $(0.038)$ & $(0.037)$ & $(0.037)$ & $(0.050)$ \\
$\mathrm{R}^{2}$ & 1283 & 1250 & 1232 & 1232 & 1239 & 1229 & 1237 \\
\hline \hline
\end{tabular}

The table presents the regression results of time 1 scores (in column) against the treatment variable, time 0 scores and time 0's pupils characteristics for the non missing strates (coeficients not displayed). Standard errors are robust and account for intra school correlation.

$* \mathrm{p}<0.1,{ }^{* *} \mathrm{p}<0.05,{ }^{* * *} \mathrm{p}<0.01$. 
exists a second, more worrisome issue when estimating effect on strata without missing values. As mentioned by Gerber and Green (2012) and Glennerster and Takavarasha (2013), dropping strata with missing values yields an unbiased treatment effect only when the potential treatment effect ${ }^{47}$ of nonrespondent schools is similar to the rest of the sample (i.e., the potential outcomes are not a function of attrition) 48 Yet this problem is arguably less likely to occur than "traditional" attrition bias 49 Besides, the fact that treatment effects are very similar in both sub-samples should convince that such selection on potential treatment effect should not be a major problem in my case. In all, although this is not a definitive proof, the fact that results are not significantly different on this sub-sample constitute an extra argument in favor of an absence of attrition bias.

\subsection{Controlling for School and Teacher Characteristics}

As mentioned earlier, another potential source of bias may come from the fact that treatment and control schools were initially not comparable. This would occur if, for instance, school district managers had selected better performing schools (and teachers) into the treatment. As seen in Table 2, schools in the treatment and control groups do not seem to present very different characteristics. In the following table, I use the school level characteristics presented in Table 2 to re-estimate the VAM1.

Controlling for school-level characteristics do not modify results systematically from Table 8; they are similar and positive in reading skills, similar and close to zero in comprehension and vocabulary, and may be slightly smaller in phonological skills and letter recognition. They are never different to the extent that this new specification would change the global interpretation: results are still very much positive and significant. Since controlling for school characteristics is certainly the more comprehensive model, I consider the

\footnotetext{
${ }^{47}$ I here call "potential treatment effect" the difference between the potential effect when treated and when not treated, potential because only one of the two statuses is observed, and thus treatment effect can't be assessed for each individual.

${ }^{48}$ Imagine that the sample is composed of specific schools that refuse to respond when they are control, yet would respond if assigned to treatment. Let's imagine these schools have a high return from the training program (the teachers or district managers were more convinced by this new approach, students more receptive to it, or similar) and thus have a larger treatment effect size than the other schools. If strata with missing schools are dropped from the sample, the "high return" schools will be dropped, together with their whole strata, only when they are in control. As a result, the remaining strata are likely to have a higher share of high-return schools and hence estimation to be biased upward.

${ }^{49}$ It would occur only when (1) the non respondent schools have different returns from the program than other schools, and (2) high-return schools in the treatment group (in the example given in footnote 48), and which responded to the survey, belong to strata without missing schools.
} 
Table 12: Value Added Model 1 - Controlling for School Level Characteristics

\begin{tabular}{lcccccccc}
\hline \hline & $\begin{array}{c}\text { Voca- } \\
\text { bulary }\end{array}$ & $\begin{array}{c}\text { Letter } \\
\text { recognition }\end{array}$ & $\begin{array}{c}\text { Compre- } \\
\text { hension }\end{array}$ & $\begin{array}{c}\text { Sounds } \\
\text { recognition }\end{array}$ & $\begin{array}{c}\text { Segmen- } \\
\text { tation }\end{array}$ & $\begin{array}{c}\text { Pseudo } \\
\text { reading }\end{array}$ & $\begin{array}{c}\text { Lexical } \\
\text { reading }\end{array}$ \\
\hline Treatment school & -0.069 & $0.110^{* * *}$ & 0.083 & $0.150^{* *}$ & $0.211^{* * *}$ & $0.438^{* * *}$ & $0.134^{* *}$ \\
& $(0.058)$ & $(0.034)$ & $(0.056)$ & $(0.059)$ & $(0.054)$ & $(0.065)$ & $(0.062)$ \\
Baseline test scores & & & & & & & & \\
Vocabulary & $0.424^{* * *}$ & 0.023 & $0.167^{* * *}$ & $0.105^{* * *}$ & $0.141^{* * *}$ & 0.013 & 0.001 \\
& $(0.034)$ & $(0.023)$ & $(0.023)$ & $(0.022)$ & $(0.027)$ & $(0.024)$ & $(0.021)$ \\
Letter & $0.076^{* * *}$ & $0.494^{* * *}$ & 0.018 & $0.148^{* * *}$ & $0.129^{* * *}$ & $0.319^{* * *}$ & $0.161^{* * *}$ \\
& $(0.020)$ & $(0.032)$ & $(0.016)$ & $(0.020)$ & $(0.017)$ & $(0.021)$ & $(0.020)$ \\
Comprehension & $0.103^{* * *}$ & -0.026 & $0.331^{* * *}$ & $0.075^{* * *}$ & $0.122^{* * *}$ & 0.017 & 0.023 \\
& $(0.020)$ & $(0.019)$ & $(0.019)$ & $(0.022)$ & $(0.021)$ & $(0.021)$ & $(0.027)$ \\
Phonology & $0.038^{* *}$ & $0.029^{*}$ & $0.127^{* * *}$ & $0.278^{* * *}$ & $0.187^{* * *}$ & $0.260^{* * *}$ & $0.277^{* * *}$ \\
& $(0.016)$ & $(0.016)$ & $(0.020)$ & $(0.023)$ & $(0.026)$ & $(0.023)$ & $(0.029)$ \\
\hline Observations & 3087 & 3053 & 3012 & 3022 & 3024 & 2977 & 2981 \\
$\mathrm{R}^{2}$ & 0.412 & 0.367 & 0.427 & 0.311 & 0.312 & 0.345 & 0.201 \\
\hline \hline
\end{tabular}

The table presents the regression results of time 1 scores (in column) against the treatment variable, time 0 scores and time 0 pupils characteristics (not diplayed) and school level characteristics (not displayed). Standard errors are robust and account for intra school correlation.

${ }^{*} \mathrm{p}<0.1,{ }^{* *} \mathrm{p}<0.05,{ }^{* * *} \mathrm{p}<0.01$. 
estimates found here as the final results of this study.

A second set of potential sources of selection are teachers. As shown in Table 4, some teacher characteristics are correlated to students' follow-up results: experience, higher education attainment, and higher education track. Unfortunately, such data were not collected on all the schools. I thus restrict the analysis to the two districts where data were collected on teachers and present VAM1 results in Table 13.50

Table 13: Impact using VAM1: 62 AND 92 Sample

\begin{tabular}{|c|c|c|c|c|c|c|c|c|c|}
\hline \multirow[b]{3}{*}{ Vocabulary } & \multicolumn{3}{|c|}{ Student Controls } & \multicolumn{3}{|c|}{ School controls } & \multicolumn{3}{|c|}{ Teachers controls } \\
\hline & $\mathrm{N}$ & Clust. & Coef. & $\mathrm{N}$ & Clust. & Coef. & $\mathrm{N}$ & Clust. & Coef. \\
\hline & 987 & 24 & $\begin{array}{c}0.101 \\
(0.089)\end{array}$ & 987 & 24 & $\begin{array}{c}\theta .021 \\
(0.073)\end{array}$ & 987 & 24 & $\begin{array}{c}0.051 \\
(0.099)\end{array}$ \\
\hline Letter & 986 & 24 & $\begin{array}{l}0.266^{* * *} \\
(0.057)\end{array}$ & 986 & 24 & $\begin{array}{l}0.219^{* * *} \\
(0.077)\end{array}$ & 986 & 24 & $\begin{array}{c}0.17^{*} \\
(0.089)\end{array}$ \\
\hline Comprehension & 983 & 24 & $\begin{array}{c}0.012 \\
(0.121)\end{array}$ & 983 & 24 & $\begin{array}{c}\theta .284^{* *} \\
(0.116)\end{array}$ & 983 & 24 & $\begin{array}{r}0.217 \\
(0.14)\end{array}$ \\
\hline Sound recognition & 985 & 24 & $\begin{array}{l}0.265^{* * *} \\
(0.092)\end{array}$ & 985 & 24 & $\begin{array}{l}0.308^{* * *} \\
(0.078)\end{array}$ & 985 & 24 & $\begin{array}{c}0.199 \\
(0.126)\end{array}$ \\
\hline Segmentation & 983 & 24 & $\begin{array}{l}0.251^{* * *} \\
(0.083)\end{array}$ & 983 & 24 & $\begin{array}{c}0.112^{*} \\
(0.059)\end{array}$ & 983 & 24 & $\begin{array}{c}0.091 \\
(0.143)\end{array}$ \\
\hline Pseudo reading & 979 & 24 & $\begin{array}{l}0.555^{* * *} \\
(0.101)\end{array}$ & 979 & 24 & $\begin{array}{l}0.606^{* * *} \\
(0.098)\end{array}$ & 979 & 24 & $\begin{array}{l}0.532^{* * *} \\
(0.093)\end{array}$ \\
\hline Lexical reading & 982 & 24 & $\begin{array}{c}0.126 \\
(0.095)\end{array}$ & 982 & 24 & $\begin{array}{c}0.042 \\
(0.083)\end{array}$ & 982 & 24 & $\begin{array}{c}0.105 \\
(0.099)\end{array}$ \\
\hline
\end{tabular}

The table presents the treatment effects estimated using the VAM 1 for the school district 62 and 92 and for different specifications. Student controls include baseline test scores, age trimester dummies, gender and whether the child holds a traditional french first name. For each score, the table gives in columns the number of pupils who took the test $(\mathrm{Obs})$, the number of schools which administered it (Clust) and the standardized difference between the treatment and the control (Coef) group with their respective robust standard error below in parentheses.

${ }^{*} \mathrm{p}<0.1,{ }^{* *} \mathrm{p}<0.05,{ }^{* * *} \mathrm{p}<0.01$.

Given the small sample, coefficients are less precisely estimated, but results seem not to have systematically been affected in one direction. When controlled for school-level characteristics, results seem to be driven slightly downward, as for the full sample. They

\footnotetext{
${ }^{50}$ Besides, lack of degree of freedom at the cluster level makes inconsistent estimates on that sub-sample. I thus remove the strata fixed effect in this sub-analysis.
} 
are somehow smaller in vocabulary, letter recognition, and lexical reading, but larger on pseudo-reading and sounds recognition. Results on comprehension are driven down more clearly. When teacher variables are added, results become weakly significant (probably due to additional noise in teacher measures) but do not change systematically in one direction (three increase, four decrease). In any case, none of these estimates are affected sufficiently to be statistically distinguishable from the results found when control for school level characteristics. As analyzed in Tables 3 and 5, while control and treatment teachers do not always present similar characteristics, one cannot presume the direction of the bias: the higher level of experience in the treatment group seems to be offset by the lower higher education attainment.

Table 14: Treatment effect : Aggregate results

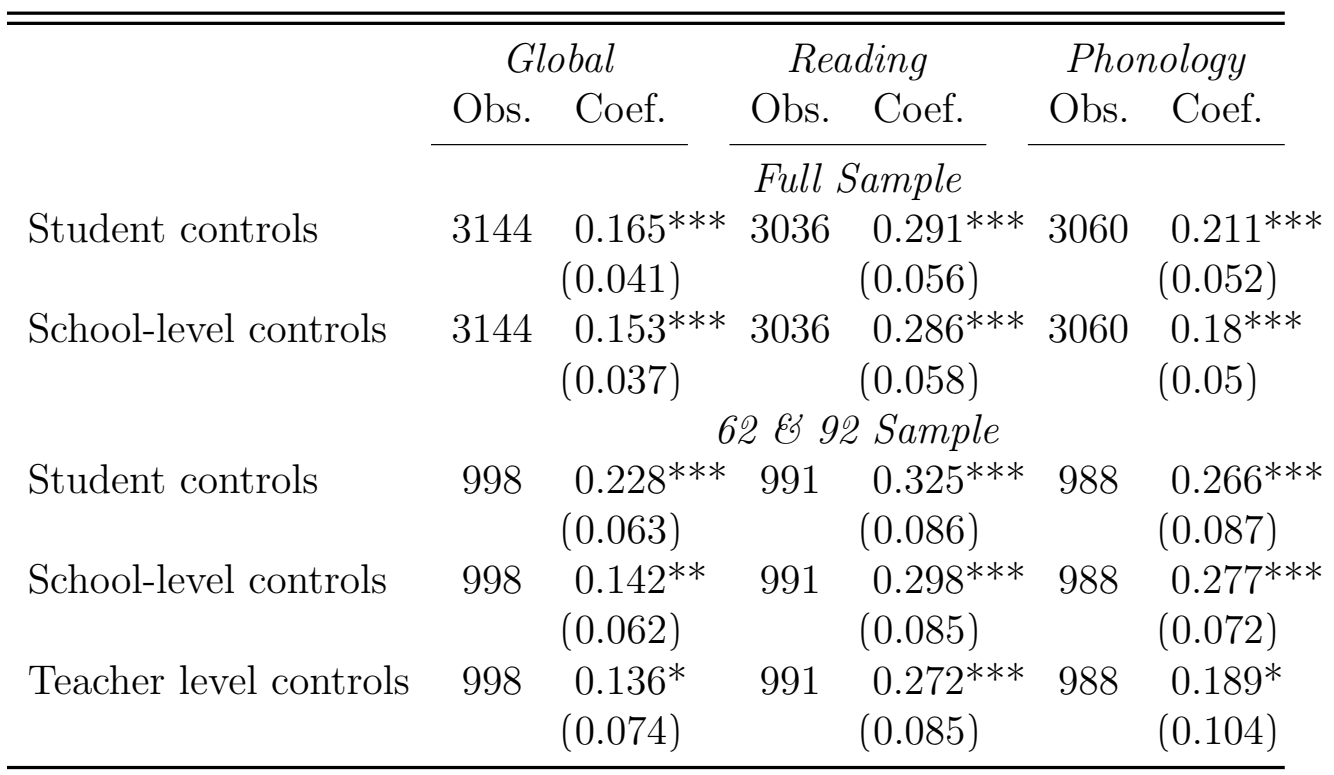

The table presents the Seemingly Unrelated Regression results for three aggregate indexes. Overall is an aggregate measure of all subitems administered at endline, Reading a composition of pseudo and lexical reading competences and Phonology an aggregate of sounds recogition and segmentation. Robust and clustered-at-schoollevel standard errors are displayed in parentheses below the coefficient. Scores are standardized using the standard deviation of the control group.

$* 10 \%$ significance level, ${ }^{* *} 5 \%$ significance level, ${ }^{* * *} 1 \%$ significance level

Finally, to reach a more general statement on the overall effect of teacher control variables, I re-estimate the treatment effect on indexes on the same sub-sample as in Table 13. On the full sample, results are driven down slightly when school-level characteristics are added, confirming that responding treatment schools were slightly better schools than the 
respective controls. Yet results on the global aggregate measure remain positive and significant at $15.3 \%$ of a standard deviation. All indexes are only slightly affected by additional control, the direction of the bias being uncertain.

\section{Conclusion}

Several important findings can be drawn from this analysis. First, as shown in Table 3, teachers' practices can be affected by an intensive training program; treatment group teachers report working in small groups more often, are less likely to work in non-tracked small groups, and seem to devote less time to non-reading activity. I show that the new teaching practices introduced in class had a positive and strong effect on early reading skills: depending on the competence considered, when positive, impacts range from $11 \%$ to $44 \%$ of a standard deviation, for an overall effect of $15.3 \%$ of a sd. Effects are particularly strong in competences that were directly stimulated by the program (pseudo-reading), while competences only indirectly stimulated were impacted either weakly (letter recognition) or not at all (vocabulary comprehension). Overall results are smaller than the those found in Israel (Angrist and Lavy, 2001) or France (Bressoux et al., 2009), but the intensity, length, take-up, and context render a direct comparison irrelevant. My results are more comparable to the ones found in UK (Machin and McNally (2008)) on an overall reading index $(+8.3 \%)$. Second, the program studied here is much more cost-effective than the benchmark studies on class-size reduction. While it is more costly than the English one $5 €$ per percentage point gain in England against $13 €$ per pp gain in France, probably due to the close monitoring implemented in France and the fact that the English project was more scaled up - it fares well when compared with other resource-only policies such as class-size reduction program ( whose cost is estimated between 36 and 48 ? per pp gain). This is without accounting for the long-term effects: if teachers are able to reproduce the good practices learned during the training over the years, it would be hard to imagine a more cost effective education policies than effective teacher training programs. This result hence reaffirms the central role that teachers play in the overall efficiency of an education system.

Thirdly, the analysis stresses the fact that the program had a differential impact on children depending on their initial level. Progress was stronger for weak children on less- 
advanced domains (phonology letter recognition), while everyone seems to have benefited from the program on more advanced ones (reading). These differential impacts are probably a consequence of the four achievement groups formed at the beginning of the year and of the explicit teaching approach undertaken. In the French education system, known to be particularly ill adept at reducing the initial social and cognitive gap, such results are particularly meaningful. Besides, they echo other results found in developing countries, such as Duflo et al. (2011), and reinforce the idea that teaching at the right level is a very powerful approach to improve the education supply. An audacious observer might even suggest that many of the classical supply-side education policies' impact (class-size reduction, computer-assisted teaching, remedial education, boarding school, charter school, and so on) could be analyzed in light of these findings. Some policies may help in teaching to the right level (new pedagogy, computer-assisted teaching, class-size reduction), while some others may help in reducing initial achievement variance (tracking, class-size reduction).

Finally, this article contributes to a more general debate on the way teachers should be managed and trained. While it seems clear that monitoring, selecting, and incentivizing teachers is a way to improve education supply, this and other recent studies stress the fact that, as with any job, teaching, especially teaching how to read, requires concrete skills and practices that can be transmitted. To move forward, we need further evidence, possibly using exogeneous program assignment. How do such programs affect children and teachers in the long run? Are there negative spillovers on other competences (non-cognitive competences or mathematics, for instance)? Is the end of kindergarten the right time for such programs? These are all legitimate questions that remain to be investigated further. 


\section{References}

Angrist, J. D. and Lavy, V. (2001). Does teacher training affect pupil learning? evidence from matched comparisons in jerusalem public schools. Journal of Labor Economics, 19(2):343-69. 6, 45

Banerjee, A. V., Banerji, R., Duflo, E., Glennerster, R., and Khemani, S. (2010). Pitfalls of Participatory Programs: Evidence from a Randomized Evaluation in Education in India. American Economic Journal: Economic Policy, 2(1):1-30. 4

Banerjee, A. V., Cole, S., Duflo, E., and Linden, L. (2007). Remedying education: Evidence from two randomized experiments in india. The Quarterly Journal of Economics, 122(3):1235-1264. 4

Bougnères, A., Suchaut, B., and Bouguen, A. (2014). Sept minutes pour apprendre à lire. Working paper. 14

Boyd, D., Grossman, P., Lankford, H., Loeb, S., and Wyckoff, J. (2009). Teacher preparation and student achievement. Education Evaluation and Policy Analysis, 31(4). 5

Bressoux, P., Kramarz, F., and Prost, C. (2009). Teachers' training, class size and students' outcomes: Learning from administrative forecasting mistakes. Economic Journal, 119(536):540-561. 2, 4, 6, 27, 39, 45

Bressoux, P. and Lima, L. (2011). La place de l'évaluation dans les politiques éducatives: le cas de la taille des classes à l' école primaire en france. Raisons Educatives, 15:99-123. 2. 4

DEPP (2010). Etat de l'ecole, 30 indicateurs sur le système éducatif français. Technical report, Département de l'Evaluation, de la Prospective et de la Performance, Ministère de l'Education Nationale. 18

DEPP (2013). Etat de l'ecole, 30 indicateurs sur le système éducatif français. Technical report, Département de l'Evaluation, de la Prospective et de la Performance, Ministère de l'Education Nationale. 13

Duflo, E., Dupas, P., and Kremer, M. (2011). Peer effects, teacher incentives, and the impact of tracking: Evidence from a randomized evaluation in kenya. American Economic Review, 101(5):1739-74. 4, 38, 46

Garet, M., Cronen, S., Eaton, M., Kurki, A., Meredith, L., Wehmah, J., Kazuaki, U., Falk, A., Bloom, H., Doolitlle, F., Zhu, P., Sztejnberg, L., and Silverberg, M. (2008). The impact of two professional development interventions on early reading instruction and achievement. Technical report, Institute of Education Sciences. 7 
Garet, M. S., Wayne, A. J., Stancavage, F., , Taylor, J., Eaton, M., Walters, K., Song, M., Brown, S., and Hurlburt, S. (2011). Middle school mathematics professional development impact study. Technical report, Institute of Education Sciences. 7

Gentaz, E., Sprenger-Charolles, L., Colé, P., Theurel, A., Gurgand, M., Huron, C., Rocher, T., and Le Cam, M. (2013). Evaluation quantitative dún entrainement à la lecture à grande échelle pour des enfants de cp scolarisés en réseaux d'éducation prioritaire: Apports et limites. Approche Neuropsychologique des Apprentissages chez l'Enfant, 123. 7

Gerber, A. and Green, D. (2012). Field Experiments: Design, Analysis and Interpretation. W.W.Norton Company. 41

Glennerster, R. and Takavarasha, K. (2013). Running randomized evaluation, A practical guide. Princeton University Press. 41.

Goldhaber, D., Liddle, S., and Theobald, R. (2013). The gateway to the profession: Assessing teacher preparation programs based on student achievement. Economics of Education Review, 34(C):29-44. 5

Greene, W. (2003). Econometric Analysis. 49, 54

Hanushek, Jackson, and Rossi (1977). Statistical Method for Social Scientist. New York: Academic Press. 51

Hanushek, E. (1971). Teacher Characteristics and Gains in Student Achievement: Estimation Using Micro Data. American Economic Review, 61(2):280-88. 2, 5

Hanushek, E. A. (1986). The economics of schooling: Production and efficiency in public schools. Journal of Economic Literature, 24(3):1141-77. 12

Hanushek, E. A., Kain, J. F., O'Brien, D. M., and Rivkin, S. G. (2005). The Market for Teacher Quality. NBER Working Papers 11154, National Bureau of Economic Research, Inc. 12

Harris, D. N. and Sass, T. R. (2011). Teacher training, teacher quality and student achievement. Journal of Public Economics, 95(7-8):798-812. 2, 5, 23

Jeffrey R. Kling, Jeffrey B. Liebman, L. F. K. (2007). Experimental analysis of neighborhood effects. Econometrica, 75(1):83-119. 37

Kane, T. J. and Staiger, D. O. (2008). Estimating teacher impacts on student achievement: An experimental evaluation. NBER Working Papers 14607, National Bureau of Economic Research, Inc. 5

Koedel, C., Ehlert, M., Podgursky, M., and Parsons, E. (2012). Teacher Preparation Programs and Teacher Quality: Are There Real Differences Across Programs? Working Papers 1204, Department of Economics, University of Missouri. 5 
Machin, S. and McNally, S. (2008). The literacy hour. Journal of Public Economics, 92(5-6):1441-1462. 7, 45

Manski, C. F. (1993). Identification of endogenous social effects: The reflection problem. Review of Economic Studies, 60(3):531-42. 32

National Reading Panel (1999). Teaching children to read. Technical report, National Reading Panel. 7, 14

NICHD (2005). Pathway to reading: The role of oral language in the transition to reading. Development Psychology, 41(2):428-442. 7

Nye, B., Konstantopoulous, S., and V.Hedges, L. (2004). How large are teacher effects? Educational Evaluation and Policy Analysis, 26(3):237-257. 2

Piketty, T. and Valdenaire, M. (2006). L'impact de la taille des classes sur la réussite scolaire dans les écoles, colléges et lycés francais. Technical report, Ministère de l'éducation Nationale. 2, 4

Rivkin, S. G., Hanushek, E. A., and Kain, J. F. (2005). Teachers, schools, and academic achievement. Econometrica, 73(2):417-458. 2, 5

Rockoff, J. E. (2004). The Impact of Individual Teachers on Student Achievement: Evidence from Panel Data. American Economic Review, paper and proceedings, 94(2):247252. 2

Schatschneider, C., J.Francis, D., Carlson, C., Fletcher, J., and B.Foorman (2004). Kindergarten prediction of reading skills: A longitudinal comparative analysis. Journal of Educational Psychology, 96(2):265-282. 6, 7

Storch, S. and Whitehurst, G. (2002). Oral language and coded-related precursors to reading: evidences from a longitudinal structural model. Development Psychology, 38(6):265282. 7

\section{Appendix A : Low bound estimate}

In section 3, we use a well-known result from Greene (2003) to the expression of the omitted bias created in that case. Greene (2003) [p.148] states that :

$$
E(\hat{\boldsymbol{\alpha}})=\boldsymbol{\alpha}+\left(X_{1}^{\prime} X_{1}\right)^{-1}\left(X_{1}^{\prime} X_{2}\right) \boldsymbol{\alpha}_{2}
$$

where $\mathbf{X}_{1}$ are explanatory variables included in the model and $\mathbf{X}_{\mathbf{2}}$ are the ones omitted. According to (8), the omitted variable is the error term $\epsilon_{0}$,and the explained part includes two vectors $\mathbf{T}$ and $\boldsymbol{A}_{\mathfrak{o}}$ and is hence a nx2 matrix. $\boldsymbol{\alpha}$ is a column vector $2 \mathrm{x} 1$ composed of 
two parameters $\beta$ and $\gamma$ and $\boldsymbol{\alpha}_{2}$ is scalar $\gamma$. Note that according to (8), $\gamma$ comes in the model with a negative sign. The bias of the VAM 1 estimator :

$$
E(\hat{\boldsymbol{\alpha}})=\boldsymbol{\alpha}-\left(\mathbf{X}^{\prime} \mathbf{X}\right)^{-1}\left(\mathbf{X}^{\prime} \boldsymbol{\epsilon}_{\mathbf{i} 0}\right) \gamma
$$

with $\mathbf{X}=\left[\begin{array}{ccc}1 & A_{01} & T_{1} \\ \vdots & \vdots & \\ 1 & A_{0 n} & T_{n}\end{array}\right], \epsilon_{0}=\left[\begin{array}{c}\epsilon_{1,0} \\ \vdots \\ \epsilon_{n, 0}\end{array}\right], \boldsymbol{\alpha}=\left[\begin{array}{c}\beta_{0} \\ \gamma \\ \beta_{1}\end{array}\right]$.

with,

$$
\mathbf{X}^{\prime} \mathbf{X}=\left[\begin{array}{ccc}
\mathrm{N} & \sum \mathrm{A}_{\mathrm{i} 0} & \sum \mathrm{T}_{\mathrm{i}} \\
\sum \mathrm{A}_{\mathrm{i} 0} & \sum \mathrm{A}_{\mathrm{i} 0}^{2} & \sum \mathrm{A}_{\mathrm{i} 0} \mathrm{~T}_{\mathrm{i}} \\
\sum \mathrm{T}_{\mathrm{i}} & \sum \mathrm{A}_{\mathrm{i} 0} \mathrm{~T}_{\mathrm{i}} & \sum \mathrm{T}_{\mathrm{i}}^{2}
\end{array}\right]=\left(\mathbf{X}^{\prime} \mathbf{X}\right)^{\prime}
$$

\section{Determinant of XX}

$$
\begin{aligned}
\operatorname{det}\left(X^{\prime} X\right)= & \sum A^{2} T^{2}-\left(\sum A_{0} T\right)^{2} \\
& -\bar{A}_{0} \sum A_{0} \sum T^{2}+\bar{A}_{0} \sum \mathrm{T} \sum A_{0} T \\
& +\bar{T} \sum A_{0} \sum A_{0}-\bar{T} \sum A_{0}^{2} \sum{ }^{T}
\end{aligned}
$$

with $\overline{\mathrm{T}}=1 / \mathrm{N} \sum \mathrm{T}$ and $\overline{\mathrm{A}}=1 / \mathrm{N} \sum \mathrm{A}$.

Adding and subtracting $n^{2} \bar{\top}^{2}{\overline{A_{0}}}^{2}$, and regrouping the terms, we get:

$$
\begin{aligned}
\operatorname{det}\left(X^{\prime} X\right)= & \sum A^{2} T^{2}-\overline{A_{0}} \sum A_{0} \sum T^{2}-\bar{T} \sum A_{0}^{2} \sum T+n^{2} \bar{T}^{2} \bar{A}_{0}^{2} \\
& -\left[\left(\sum A_{0} T\right)^{2}-2 n \bar{A}_{0} \bar{T} \sum T A_{0}+n^{2} \bar{T}^{2} \bar{A}_{0}^{2}\right] \\
\operatorname{det}\left(X^{\prime} X\right)= & \left(\sum A_{0}^{2}-n \bar{A}_{0}^{2}\right)\left(\sum T^{2}-n \bar{T}^{2}\right) \\
& -\left(\sum A_{0} T-n \bar{T} \bar{A}_{0}\right)^{2} \\
= & V\left(A_{0}\right) V(T)-C\left(A_{0}, T\right)
\end{aligned}
$$

with :

$$
\begin{aligned}
V\left(A_{0}\right) & \left.=\sum A_{0}^{2}-n \bar{A}_{0}^{2}\right) \\
V(T) & =\sum T^{2}-n \bar{T}^{2} \\
C\left(A_{0}, T\right) & =\sum A_{0} T-n \bar{T} \bar{A}_{0}
\end{aligned}
$$




\section{Inverting the matrix $\left(X^{-1}\right)$}

$$
\left(X^{\prime} X\right)^{-1}=\frac{1}{V\left(A_{0}\right) V(T)-C\left(A_{0}, T\right)}\left[\begin{array}{ccc}
\left|M_{1,1}\right| & -\left|M_{1,2}\right| & \left|M_{1,3}\right| \\
-\left|M_{2,1}\right| & \left|M_{2,2}\right| & -\left|M_{2,3}\right| \\
\mid M_{3,1} & -\left|M_{3,2}\right| & \left|M_{3,3}\right|
\end{array}\right]
$$

where the $\mathrm{M}_{\mathrm{i}, \mathrm{j}} \mathrm{s}$ form the matrix of minor of (X'X)'.

Matrix product

$X^{\prime} \epsilon_{0}=\left[\begin{array}{c}\sum \epsilon_{i 0} \\ \sum A_{0 i} \epsilon_{i 0} \\ \sum T_{i} \epsilon_{i 0}\end{array}\right]$

and finally

$$
E(\hat{\boldsymbol{\alpha}})=\left[\begin{array}{c}
\beta_{0} \\
\gamma \\
\beta_{1}
\end{array}\right]-\frac{1}{V\left(A_{0}\right) V(T)-C\left(A_{0}, T\right)^{2}}\left[\begin{array}{c}
\sum \epsilon_{i 0} \\
\sum A_{0 i} \epsilon_{i 0} \\
\sum T_{i} \epsilon_{i 0}
\end{array}\right]\left[\begin{array}{ccc}
\left|M_{1,1}\right| & -\left|M_{1,2}\right| & \left|M_{1,3}\right| \\
-\left|M_{2,1}\right| & \left|M_{2,2}\right| & -\left|M_{2,3}\right| \\
\left|M_{3,1}\right| & -\left|M_{3,2}\right| & \left|M_{3,3}\right|
\end{array}\right] \gamma
$$

where each row gives the bias generated by the measurement error on the three parameters of the model $\left(\beta_{0}, \beta_{1}\right.$ and $\left.\gamma\right)$. It can easily be shown that the bias generated by the second row is downward (classical attenuation bias). We are primarily interested by the direction of the bias on $\beta_{1}$.

$$
\begin{aligned}
E\left(\hat{\beta_{1}}\right)=\beta- & \gamma \frac{1}{V\left(A_{0}\right) V(T)-C\left(A_{0}, T\right)^{2}} * \\
& {\left[\bar{A}_{0} \sum A_{0} T-\bar{T} \sum A_{0}^{2}\right) \sum \epsilon_{i 0}-\sum A_{0 i} \epsilon_{i 0}\left(\sum A_{0} T-\bar{A}_{0} \bar{T}\right)+\sum T_{i} \epsilon_{i 0}\left(\sum A_{0}^{2}-\bar{A}_{0}^{2}\right] }
\end{aligned}
$$

Adding and subtracting $n^{2} \hat{A}_{0}^{2} \hat{\epsilon}_{0} \hat{T}$, and rearranging terms, I get:

$$
E\left(\hat{\beta}_{1}\right)=\beta-\gamma \frac{V\left(A_{0}\right) C\left(T, \epsilon_{0}\right)-C\left(A_{0}, T\right) C\left(A_{0}, \epsilon_{0}\right)}{V\left(A_{0}\right) V(T)-C\left(A_{0}, T\right)^{2}}
$$

with $\mathrm{V}$ the variance and $\mathrm{C}$ the covariance. Multiplying the denominator and numerator by $\frac{1}{V\left(A_{0}\right) V(T) S\left(\epsilon_{0}\right)}\left(\right.$ with $\left.S\left(\epsilon_{0}\right)=\sqrt{V \epsilon}\right)$, we get:

$$
E\left(\hat{\beta}_{v \mathrm{am} 1}\right)=\beta-\gamma \frac{r_{\left(\mathrm{T}, \epsilon_{0}\right)}-r\left(A_{0}, T\right) r\left(A_{0}, \epsilon\right)}{1-r_{\left(A_{0}, T\right)}^{2}} \frac{S_{\epsilon_{0}}}{S_{T}}
$$

with $\mathrm{r}$ the respective correlations. This scalar result can also be found in Hanushek et al. (1977). Besides, since in a classical measurement error model $r_{\epsilon_{0}, T}=0$ and $r_{\epsilon_{0}, A_{0}}=$ $r\left(\epsilon_{0}, \mu+\epsilon_{0}\right)=r\left(\epsilon_{0}, \epsilon_{0}\right)=V_{\epsilon}$, then : 


$$
E(\hat{\beta})=\beta+\gamma \frac{r\left(A_{0}, T\right) * V_{\epsilon_{0}}}{1-r\left(A_{0}, T\right)^{2}} \frac{S_{\epsilon_{0}}}{S_{T}}
$$

The sign of the bias is determined by $r\left(A_{0}, T\right)$ if $0<\gamma<1$. It will be the case if the process is stationary.

To look at the direction of the bias more intuitively, I present in Figure 1 a visual representation of the treatment effect under different values of $\rho$. As said, when $\rho$ equals zero, we are in the classical difference-in-differences model, where the treatment group's trend is equal to the one of the control group (first panel). Alternatively, when $\rho$ is negative, we are in a convergent model, where weaker students (here the treatment group) catch up with more advanced students. The more negative $\rho$ is, the smaller is the treatment effect. Inversely, when $\rho$ is positive, we are in a divergent model, where the gap between under-achievers (treatment group) and the others increases. As $\rho$ increases, the estimated treatment effect $\beta$ increases. As a result, a downward bias on $\rho$ will automatically produce a downward bias on $\beta$. 
Figure 1: Treatment effect under specific values of $\rho$
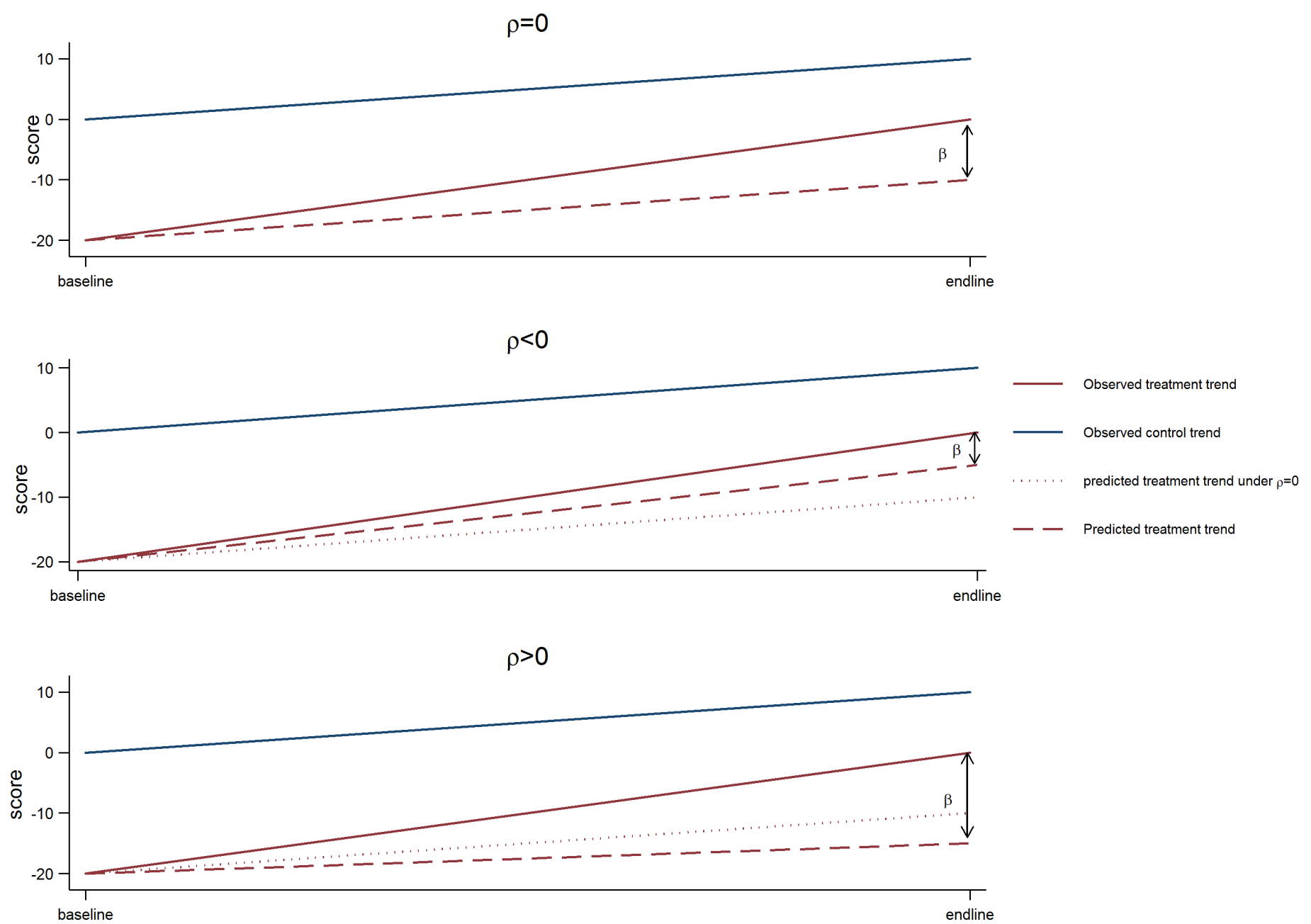


\section{Direction of the bias with additional controls}

Let's consider the case where more control variables are included in the model like in (10). We regroup into one single matrix $\mathbf{W}_{1}$ the "former" variables ( $\mathrm{T}$ and $\mathrm{A}_{0}$ ) and in the matrix $\mathbf{W}_{2}$ the additional controls $\left(\mathrm{P}_{\mathrm{s} 0}\right.$ and $\left.\mathrm{P}_{\mathrm{c} 1}\right)$. (10) becomes

$$
A_{i 1}=\alpha_{1} W_{1}+\alpha_{2} W_{2}+\iota
$$

We can define:

$$
\mathbf{M}_{2}=\mathbf{I}-\mathbf{W}_{2}\left(\mathbf{W}^{\prime}{ }_{2} \mathbf{W}_{2}\right)^{-1} \mathbf{W}^{\prime}{ }_{2}
$$

the "residual maker" that gives the following residual prediction of $A_{i 1}$ and $W_{1}$ :

$$
A_{i 1}^{*}=M_{2} A_{i 1}
$$

and

$$
\mathrm{W}_{1}^{*}=\mathrm{M}_{2} \mathrm{~W}_{1}
$$

and write:

$$
A_{i 1}^{*}=\alpha_{1} \mathbf{W}_{1}^{*}+\iota
$$

Following Frisch and waugh (see Greene (2003) [p.26]), we know that $\iota$ and $\alpha_{1}$ are similar in 17 and 16. We can hence re-apply the demonstration developed previously and show that:

$$
\mathrm{E}\left(\hat{\alpha}_{1}\right)=\alpha_{1}+\gamma \frac{\mathrm{r}\left(\mathrm{A}_{0}^{*}, \mathrm{~T}^{*}\right) * \mathrm{~V}_{\mathrm{t}_{0}}}{1-\mathrm{r}\left(\mathrm{A}_{0}^{*}, \mathrm{~S}^{*}\right)^{2}} \frac{\mathrm{L}_{\mathrm{o}}}{\mathrm{S}^{*}}
$$

with $A_{0}^{*}$ and $T^{*}$ the residual of $A_{0}$ (respectively $T^{*}$ ) when it is regressed on $\mathbf{W}_{2}$. As in 15, the sign of the bias is fully determined by $r\left(A_{0}^{*}, T^{*}\right)$. What is the sign of $r\left(A_{0}^{*}, T^{*}\right)$ ? Under (12), the fundamental assumption of the VAM models with additional controls, the $r\left(A_{0}^{*}, T^{*}\right)$ is equivalent to $r\left(A_{0}, T\right)$ and hence the 18 still gives a lower bound of the true treatment effect. 


\section{Appendix B : Estimation controlling for baseline test scores only}

Table 15: Value Added Model 1: controlled for baseline test scores only

\begin{tabular}{|c|c|c|c|c|c|c|c|}
\hline & $\begin{array}{c}(1) \\
\text { Voca- } \\
\text { bulary }\end{array}$ & $\begin{array}{c}(2) \\
\text { Letter } \\
\text { recognition }\end{array}$ & $\begin{array}{c}(3) \\
\text { Compre- } \\
\text { hension }\end{array}$ & $\begin{array}{c}(4) \\
\text { Sounds } \\
\text { recognition }\end{array}$ & $\begin{array}{c}(5) \\
\text { Segmen- } \\
\text { tation }\end{array}$ & $\begin{array}{c}(6) \\
\text { Pseudo } \\
\text { reading }\end{array}$ & $\begin{array}{c}(7) \\
\text { Lexical } \\
\text { reading }\end{array}$ \\
\hline Treatment school & $\begin{array}{r}-0.096 \\
(0.086)\end{array}$ & $\begin{array}{l}0.133^{* * *} \\
(0.032)\end{array}$ & $\begin{array}{c}0.056 \\
(0.065)\end{array}$ & $\begin{array}{c}0.130^{* *} \\
(0.059)\end{array}$ & $\begin{array}{l}0.204^{* * *} \\
(0.062)\end{array}$ & $\begin{array}{l}0.412^{* * *} \\
(0.064)\end{array}$ & $\begin{array}{c}0.110^{*} \\
(0.058)\end{array}$ \\
\hline \multicolumn{8}{|l|}{ Baseline test scores } \\
\hline Vocabulary & $\begin{array}{l}0.433^{* * *} \\
(0.035)\end{array}$ & $\begin{array}{c}0.026 \\
(0.023)\end{array}$ & $\begin{array}{l}0.179 * * * \\
(0.023)\end{array}$ & $\begin{array}{l}0.110^{* * *} \\
(0.022)\end{array}$ & $\begin{array}{l}0.148^{* * *} \\
(0.028)\end{array}$ & $\begin{array}{c}0.021 \\
(0.024)\end{array}$ & $\begin{array}{c}0.011 \\
(0.022)\end{array}$ \\
\hline Letter & $\begin{array}{l}0.077^{* * *} \\
(0.020)\end{array}$ & $\begin{array}{l}0.494^{* * *} \\
(0.032)\end{array}$ & $\begin{array}{c}0.024 \\
(0.017)\end{array}$ & $\begin{array}{l}0.155^{* * *} \\
(0.021)\end{array}$ & $\begin{array}{l}0.138^{* * *} \\
(0.017)\end{array}$ & $\begin{array}{l}0.329^{* * *} \\
(0.022)\end{array}$ & $\begin{array}{l}0.162^{\text {*** }} \\
(0.020)\end{array}$ \\
\hline Comprehension & $\begin{array}{l}0.119^{* * *} \\
(0.020)\end{array}$ & ${ }^{*}-\begin{array}{c}0.022 \\
(0.019)\end{array}$ & $\begin{array}{l}0.347^{* * *} \\
(0.019)\end{array}$ & $\begin{array}{l}0.091^{* * *} \\
(0.021)\end{array}$ & $\begin{array}{l}0.136^{* * *} \\
(0.022)\end{array}$ & $\begin{array}{c}0.029 \\
(0.022)\end{array}$ & $\begin{array}{c}0.031 \\
(0.027)\end{array}$ \\
\hline Phonology & $\begin{array}{l}0.039^{* *} \\
(0.018)\end{array}$ & $\begin{array}{c}0.030 * \\
(0.016)\end{array}$ & $\begin{array}{l}0.146^{* * * *} \\
(0.021)\end{array}$ & $\begin{array}{l}0.300^{* * *} \\
(0.025)\end{array}$ & $\begin{array}{l}0.209 * * * \\
(0.026)\end{array}$ & $\begin{array}{l}0.276^{* * * *} \\
(0.022)\end{array}$ & $\begin{array}{l}0.285^{* * *} \\
(0.029)\end{array}$ \\
\hline $\begin{array}{l}\text { Observations } \\
\mathrm{R}^{2}\end{array}$ & $\begin{array}{l}3087 \\
0.385\end{array}$ & $\begin{array}{l}3053 \\
0.364\end{array}$ & $\begin{array}{l}3012 \\
0.408\end{array}$ & $\begin{array}{l}3022 \\
0.296\end{array}$ & $\begin{array}{l}3024 \\
0.295\end{array}$ & $\begin{array}{l}2977 \\
0.327\end{array}$ & $\begin{array}{l}2981 \\
0.191\end{array}$ \\
\hline
\end{tabular}

The table presents the regression results of time 1 scores (in column) against the treatment variable, time 0 scores and time 0 pupils characteristics. Standard errors are robust and account for intra school correlation.

$* \mathrm{p}<0.1,{ }^{* *} \mathrm{p}<0.05,{ }^{* * *} \mathrm{p}<0.01$. 